\title{
Influence of Supply Chain Leagility on Performance of Humanitarian Aid Organizations in Kenya
}

\author{
Nyile Erastus Kiswili*, Ismail Noor Shale, Anthony Osoro \\ College of Human Resource Development, Jomo Kenyatta University of Agriculture and Technology, Nairobi, Kenya
}

Email address:

nyileras@gmail.com (N. E. Kiswili)

${ }^{*}$ Corresponding author

\section{To cite this article:}

Nyile Erastus Kiswili, Ismail Noor Shale, Anthony Osoro. Influence of Supply Chain Leagility on Performance of Humanitarian Aid Organizations in Kenya. Journal of Business and Economic Development. Vol. 6, No. 1, 2021, pp. 37-57. doi: 10.11648/j.jbed.20210601.15

Received: February 25, 2021; Accepted: March 9, 2021; Published: March 17, 2021

\begin{abstract}
In today's volatile and uncertain humanitarian environment, adopting a purely lean or a purely agile supply chain is not effective. Humanitarian organizations are struggling to obtain the highest possible performance from their supply chains by utilizing and adopting various supply chain designs. This is upon realization that despite the huge chunks of money pumped into humanitarian sector, stringent oversight by donors and expectations from vulnerable populations, humanitarian supply chains still respond in a sluggish, inefficient and poorly coordinated manner to emergencies. The purpose of this study was to explore the influence of supply chain responsiveness and waste management on performance of humanitarian aid organizations in Kenya. The underpinning theories and model in this study included; Decoupling Point theory; Theory of Constraints and SCOR model. Survey research design was employed for this study. The study entailed a census survey of all the 330 humanitarian aid organizations in Kenya with supply chain managers as the unit of observation. Questionnaires were used to collect primary data. Descriptive statistics and inferential statistics was used aided by SPSS version 24 to facilitate data analysis. The data was presented using a combination of statistical and graphical techniques. Trend analysis was used to spot a pattern on the sub-constructs of performance of humanitarian aid organizations for five years. The study findings revealed that supply chain responsiveness and waste management are positively associated with performance of humanitarian aid organizations. From the findings, most humanitarian aid organizations had knowingly or unknowingly partially implemented leagility design in their supply chains. The findings further showed that despite the rise in disaster resource allocation, the culture of preparedness was lacking in the country. Based on these findings and conclusions, the study recommended that to achieve and sustain an efficient and responsive supply chain, humanitarian aid organizations should design, implement and fully adopt leagility design in their humanitarian supply chains. Humanitarian aid organizations are recommended to embrace advanced technologies to improve their supply chain leagility. Donors on the other hand were encouraged to strengthen local capacity of affected communities and increase their funding on humanitarian aid operations. In addition, supply chain professionals should come up with new ways of predicting demand in a volatile, uncertain, complex and ambiguous environment learning from data from previous disasters. The study further recommends for a creation of a disaster preparedness plan that gives the way forward in times of tragedies or disasters.
\end{abstract}

Keywords: Supply Chain Responsiveness, Waste Management, Supply Chain Leagility

\section{Introduction}

Supply chain management has come out as a common art with which organizations outflank each other competition wise [1]. Organizations are making all efforts to obtain the highest possible performance from their supply chains by utilizing varied assorted means in the contemporary period [2]. Competitive edge can be achieved with no doubt when a company has adopted an effective supply chain strategy and design by utilizing its capabilities on supply chain to realize flexibility, rapid response and efficient cost. Several studies have come up with various supply chain designs, which are mutually exclusive or even collectively exhaustive such as the efficient versus responsive [3]; risk hedging, and agile [4] and market of one versus mass market. There is evidence of movement from independent supply chain patterns to hybrid 
models such as leagile supply chain as proposed by Nakandala \& Lau [5]. This backs the argument that in the current inconsistent and wavering environment, relying entirely on a purely lean or a purely agile supply chain is not guaranteed to pay off.

Conversely, natural and manmade catastrophes have substantially increased in magnitude as well as frequency in recent years. According to the United Nations, natural calamities in the coming years will increase in severity, frequency as well as damaging effect [6]. Humanitarian supply chains are responsible for provision of services in emergencies during disasters by availing food, shelter, medicine, water and sanitation [6]. When disaster containment is involved, time is an important factor as time saved means lives saved [7]. Since $80 \%$ of disaster and relief operations involve supply chains, proper chain management concepts offer possibilities to increase efficiency and effectiveness of humanitarian operations [8]. Thus, lean and agile aggregated to leagile supply chain principles are adopted following a disaster to quickly respond to it [7].

Humanitarian supply chain professionals all over the world are faced with the challenge of designing proper supply chains that meet the objective of delivering value and aid to vulnerable people at the same time satisfying donors and funders expectations. Olaogbebikan and Oloruntoba identified resemblances between commercial supply chains and humanitarian supply chains [9]. In contrast, Dubey and Gunasekaran described emphasis on life and death in place of profit and loss, unpredictability and the necessity to hastily change preference and a high number of players in the field as unique characteristics of humanitarian supply chains [10]. Worldwide, supply chain experts are in persistent quest for new and inventive methods for building productive and successful supply chains designs that will adjust to quick changes in catastrophic situations. One such design commonly adopted by humanitarian supply chains, allinclusive is the use of leagile principles in supply chains [11].

The leagile supply chain is a hybrid of lean concept and agile paradigm to form a common supply chain design [12]. The development of lean concept is credited to Toyota Company and largely the Toyota Production Systems. Lean aims at doing more with less [13]. The lean concept is essentially a combination of administrative operations with emphasis on eradication of waste in the production process inside and beyond organizations [14]. Biazzo, Panizzolo and de Crescenzo were of the view that basic principles of lean entails identifying, creating value as well as alleviating waste and generating flow [15]. The agility paradigm, which evolved from flexible manufacturing systems, focuses on the integration of the organization's suppliers, business procedures, buyers and commodity consumption and disposition [16]. An agile supply chain [17] due to its ability to dependably meet market demands, at the same time minimize expenditure, and lowering security risks better suits a changing and unpredictable business environment. This integrates flexibility as pertains to both resources and coordination of activities [18]. Attainment of resource and coordination flexibility make it possible for organizations to address the increasing environmental and operational unpredictability [19]. Thus, when talking of agility, the focus is on responding to unexpected changes in a volatile marketplace within a useful timeframe, denoting flexibility, speed, responsiveness and quality as elements of agility.

Though lean and agile principles have been used within supply chains for some time, in practice leanness does not imply agility. When markets are volatile or uncertain like in the humanitarian context, leanness should be blended with agility into a hybrid leagile strategy to create a more responsive supply chain that will deliver aid in an effective and efficient manner. The lean-agile concept has been implemented and researched in different countries globally. In Ireland, the adoption of supply chain leagility practices by humanitarian bodies is a result of donor demand for accountability and resource pressure [20]. Authors [21], using a case of the United Nations World Food Programme assessed the implementation of leagile system. The study established that due to high increase in both natural and manmade disasters, humanitarian activities have gained attention from both logistics academics and practitioners. Supply chain leagility therefore is evolving to be a vital focus of research mainly in humanitarian logistics in disaster containment operations [22].

Lean paradigm function optimally in a predictable demand, where accurate forecast can be made. Through elimination of all forms of waste, lean system have high competitive edge base on quality and cost [23]. The agility is a much diverse concept, which needs participation of the whole organization, logistics processes and information systems [24]. The agile supply chain makes organization to respond effectively in situations where there is unstable customers demand and a highly volatile market. According to Nkwunonwo, Whitworth and Baily, supply chain management is critical to humanitarian organizations operating in Nigeria. According to the study, there has been constant flooding in Lagos due low coastal location leading increased number of humanitarian organizations. Neighbors, religious homes and relatives offer aid directly to the victims. This is evidence of a miserable inference on sustainability of disaster management, humanitarian service and supply chains [25].

According to author [26], there are several complex humanitarian challenges facing East Saharan Africa arising from famines, civil wars as well as natural disasters. The population is highly prone to humanitarian calamities in comparison with the rest of the world. It also suffers from lack of national resources available to support people in times of humanitarian crisis, commonly known as coping capacity. In such circumstances, the international communities chip in to support, manage, procure and distribute most important aids. Lean and agile paradigms have attracted substantial interests currently forcing industries globally to upgrade their systems to the paradigms for purposes of fostering their performance [24]. The contemporary market trends calls for a more practical proposition that assimilate the promising facets of both lean 
and agile structures. Through this inspiration, leagility paradigm has developed as features of the two paradigms have been combined for a robust strategy. Author [26] noted that when agility first became known, leanness and agility were essentially considered different in composition and structure and agility was considered a new paradigm, which would replace leanness.

In Kenya, leagile supply chain design have been implemented by numerous humanitarian organizations and researched by different scholars. According to author [27] humanitarian organizations are important in Kenya as they have the ability to achieve impacts faster as compared to the government. As supply chain operations increase, leagile management needs to be handled with utmost professionalism since humanitarian organizations receive funding from donor institutions who expect accountability of the organizations by following laid down procurement procedures as set in the grant agreements. Leagile practices adoption within the humanitarian sector are highly desirable and this ensures that supply chain non-critical activities and operational costs are reduced to ensure higher efficiencies. Kuria examined the extent of implementation of supply chain leagility in humanitarian organizations in Kenya and how it improved their performance. The study noted the numerous humanitarian catastrophes experienced in Kenya including drought, famine, floods, disease outbreaks, food insecurity, conflict and war substantiating the intensity and significance of humanitarian activities in the country [28]. The leagile supply chain by virtue of being lean and agile, is a more superior supply chain thus enhancing performance of humanitarian organizations [29]. Leagility ensures efficiency and effectiveness along humanitarian supply chains resulting to more efficient resource utilization, reduction in response time, improved impact of activities and guarantees meeting time and expenditure targets. All this is to meet the primarily objective of the humanitarian aid organizations, which is to save lives, mitigate affliction and maintaining human decency in times of and after crisis while at the same time formulate proficiency in case of similar occurrences [30].

Weiss described a humanitarian as one who is sternly involved in advocating for the well-being of all humankind without biasness on grounds of gender, ethnicity, sexual orientation, religion or race. The goal of a humanitarian is to salvage lives, alleviate affliction and uphold human decency achieved by liberation and protection of refugees, housing and feeding the homeless, or promoting recovery from the after effects of natural disasters and civil disorder [31]. Humanitarian organizations that have effective SCM system gain from precise, accountable, fair and accurately documented procurement process. Generally, the performance of not-for-profit entities is dependent on their capability of raising funds with a view to fulfilling their goals and objectives [32]. As per the findings of Clarke, humanitarian organizations need to focus solely on presently required monetary resources and have an exclusive concentration on fundraising as well as financial indicators as this has the ability of shifting the attention from other facets of performance associated with output, effectiveness, quality in addition to client satisfaction [33].

According to Namagembe, humanitarian entities participate majorly in two forms of activities; relief and development activities [34]. Despite the huge chunks of money pumped into humanitarian sector, stringent oversight by donors and expectations from vulnerable populations, humanitarian supply chains still respond in a sluggish, inefficient and poorly coordinated manner to emergencies [35]. Mark you, about $80 \%$ of disaster and relief operations are related to supply chains [36]. The poor performance of humanitarian aid organizations is attributed to poor management of supply chain operations [37]. Thus, the inference that humanitarian aid organizations are performing way below the expected levels. Sinha [38] supports this by concluding that $50 \%$ of humanitarian aid organizations have non-performing supply chains.

This study aimed at bringing efficiency and effectiveness into humanitarian sector by looking into the concept of supply chain leagility. Predominantly, the concept was discussed in the context of commercial supply chains [39] and only a few number of academicians and practitioners have linked supply chain leagility to humanitarian operations [40]. Qamar and Hall [41] found that the two paradigms of lean and agility could not co-exist (mutually exclusive) where else Purvis [40] described them as complementary concepts. The concept of supply chain leagility has been globally accepted [42]. A number of humanitarian aid organizations have adopted leagility design despite its poor documentation limiting its full adoption, to increase efficiency in their supply chains [43]. Concisely, the employment of the leagility concept is still immature and a comprehensive overview of the concept barely exists. Previously the lean and agile paradigms have been studied separately creating the need to study them as a hybrid design and supportive of each other. This therefore creates a gap for a specific study that focuses exclusively on supply chain leagility. This study sought to fill this gap in literature by carrying out a research on the influence of supply chain leagility on performance of humanitarian aid organizations in Kenya.

\subsection{Objectives of the Study}

The general objective of this study was to determine the influence of supply chain leagility on performance of humanitarian aid organizations in Kenya. The specific objectives for this study were:

To examine the influence of supply chain responsiveness on the performance of humanitarian aid organizations in Kenya.

To determine the influence of waste management on the performance of humanitarian aid organizations in Kenya.

\subsection{Research Hypotheses}

$\mathrm{H}_{0}$ : Supply chain responsiveness does not significantly influence the performance of humanitarian aid organizations 
in Kenya.

$\mathrm{H}_{0}$ : Waste management does not significantly influence the performance of humanitarian aid organizations in Kenya.

\section{Literature Review}

The underpinning theories and models in this study included; Decoupling Point Theory; Theory, Theory of Constraints and SCOR Model.

\subsection{Decoupling Point Theory}

The Decoupling Point Theory is credited to Romme and Hoekstra [44] who intended to furnish a concept for integral control. It has since become the most common used theory in literature for supply chain responsiveness. The traditional decoupling point theory centers on a point in the supply chain where distinction is clarified among push and pull point in the pipeline. At the point, the Order Decoupling Point (ODP) is sporadically used as a critical stock point, with the supplies of the final product being held up to the time the end clients need them. Thus, the ODP give assurance to upstream players against fluctuating demand enabling them to accomplish smooth system dynamics. This implies they distinguish forecast driven (upstream) from demand driven (downstream) pull part [45].

Leagility on the other hand need both side of the ODP to utilize pull scheduling and thus create conflict. According to Goldratt, the solution to the push-pull challenge, requires consideration of an informative supply chain, where the demand data is utilized to a given upstream point in the pipeline [45]. Consequently, market sensitivity is arrived at in significant part of the supply chain, which allows for enhanced responsiveness. Their argument is that for purposes of attaining the information-augmented chain, firms need to separate the ODP in a physical and an information decoupling point. The physical Decoupling Point can additionally be used following a postponement strategy, which enables organizations to produce in advance while simultaneously deferring the last get together up to the point customized end customer demand is established. In doing this, organizations create capacity of delivering the various modules ahead of time, making of framework elements just as economies of scale. At the point when one fuse the information decoupling point (IDP), entities that are further upstream can utilize real-time demand information in their ordering and creation tasks, permitting them to accomplish more market-affectability. Such firms create client responsiveness. Taking into account that supply chain is seen as agile as the responsiveness of the least responsive player, this cultivates the responsiveness of the whole chain. Thus, lead times and inventories are limited, accelerating measures and improving the efficiency of the chain.

According to this theory, the supply chain responsiveness can be increased by relocating the decoupling points in the supply chain. Hence, the theory aid the present study by highlighting how the supply chain responsiveness objective can be attained. One factor that affect the responsiveness of the supply chain is having long lead-time. With the rapidly changing requirements, there has been a need for shorter lead-time and increased responsiveness. Humanitarian organizations have reacted to this by shifting the decoupling point upstream in the supply chain. In order to remain responsive, humanitarian organizations have focused on the internet advancement to establish high-speed information exchange and enable access to first-hand information, product standardization and modularization, associating with suppliers that deliver the ordered amounts at the agreed place in the right time and fast transportation structures. All these are the premise of the Decoupling Point theory and they assist in increasing the supply chain responsiveness. This theory underpins the study and instigates research hypothesis one:

$\mathrm{H}_{0}$ : Supply chain responsiveness does not significantly influence the performance of humanitarian aid organizations in Kenya.

\subsection{Theory of Constraints}

The theory of constraints whose proponent is Eliyahu Goldratt is a methodology used in the identification of the most critical limiting factor or constraint hindering the attainment of a goal through systematic advancement of constraint until it is no longer a limiting factor [46]. The theory construes that managers need to focus primarily on effective management of capacity and capability of the limited number of constraints contained in the organization where the performance of the organization is fostered. The key notion of the theory is that constraints limit the performance for any system within the organization. This theory assumes a scientific viewpoint to advancement and that all complex systems encompasses numerous linked activities, among them is a constraint to the entire system. To assist the attainment of system goals, the theory advances a methodology for identification and elimination of constraints, tools for analysis and resolution of problems and a method of performance measurement and guidance of management decisions [46].

This theory treats the supply chain as a system, which is a group of connected components that operate together to convert investment to value in accordance with the expectations. The theory focuses on comprehension and handling of constraints that stand between an organization and the attainment of its goals. Therefore, it avails the necessary resources, which can be effectively used by humanitarian supply chains to increase their productivity and reliability. Leagility paradigm upholds convergence of accessible resources, which is the basic notion of exploiting constraints in a supply chain. Leagile principles can be applied to maximum advantage in humanitarian supply chains to eliminate waste, trim costs, compress lead times, boost the amplitude and foster adaptability and improve flexibility and responsiveness. This without a doubt fosters humanitarian performance through ensuring optimum resource utilization, increase saved lives, meeting time, expenditure targets and needs of aid recipients and enhanced 
impact of activities and projects.

The theory of constraint in this study help in understanding the objective of waste management. According to the theory, organizations need to identify the most limiting factor or constraint standing in the way of realizing an objective and then analytically refining the constraint until it is no longer the limiting factor. The theory views waste as the largest constraint on opportunity and thus the need to be managed and eliminated for performance of humanitarian aid organizations. This theory instigates the third research hypothesis:

$\mathrm{H}_{0}$ : Waste management does not significantly influence the performance of humanitarian aid organizations in Kenya.

\subsection{Supply Chain Operations Reference (SCOR) Model}

The Supply Chain Operations Reference model (SCOR) was created and upheld by the Supply Chain Council (SCC) as the cross-industry standard for supply chain management. The SCC was set up in 1996 by Pittiglio Rabin Todd and McGrath (PRTM) and Advanced Manufacturing Research (AMR). The SCOR model was developed by the supply chain council with the assistance of 70 world leading manufacturing companies in 1996. The model views supply chain management (SCM) as a critical focus for organizations since it includes everything involved in the flow of goods from the organization to its customers, clients or to other businesses. The model established that supply chain involves more than just setting up, as it has to be constantly assessed for it to be reliable and productive to an organization. The Supply Chain Operations Reference (SCOR) model was designed to effectively manage these processes and to evaluate them for effectiveness and efficiency. Supply chain management is complex, but the SCOR model helps balance the process and come up with a computable way to determine the outcome. It is designed to operate across industries applying basic terms that can be used with any supply chain system. The SCOR design helps organizations decide whether a particular supply chain process fits the goals of the organization.

The SCOR model is a process designated to figure out waste, come up with measures, and constantly upgrade. It is a recurrent scheme of regular involvement and detection, designed to outline all the exercises related with customer/client satisfaction. The supply chain operations reference model (SCOR) is a management tool used to address, improve, and convey supply chain management decisions in an organization. The model depicts the business measures needed to fulfill a client/customer's requests, assists with clarifying the cycles along the entire supply chain and gives a premise to progress of those processes.

The SCOR model is constructed on the basis of three fundamental ideologies; process modeling/ re-engineering, measuring performance, as well as best practices. The model also constitutes five varied process-modeling including plan, source, make, deliver and return. These elements are designed to provide an organized structure and common language for supply chain management professionals. The SCOR Model also serves as an organizing framework for benchmarking supply chain activities and is useful for reengineering an organization's supply chain.

SCOR model is relevant to leagile paradigm as both are aimed at improvement of the supply chain practices. According to Supply Chain Council (2002), supply chain improvement is an explicit objective connected with the SCOR model. The SCOR model begins by looking at three levels of process details, then the application of "best practices" and the concept of configurability by which the supply chain can be improved. Similarly, leagile structure permits firms and organizations to shape a proper profile to confront effectively the volatility of markets and battle to gain competitive advantages and continuous improvement. SCOR model introduced agility as an exhibition property suggesting the ability to react to outside impacts and market place changes to pick up or keep up upper hand.

SCOR model is particularly related to waste management variable. SCOR covers three stages of technicalities (top, configuration and process element). In top, the expectation and creation for the supply chain are described, at the configuration level the company's supply chain is configured in order to company strategy, at the process element level there is a "fine tuning" of company's operations strategy. The configuration level of SCOR provides a rare opportunity for addressing waste. This is where core process strategies are set and where companies align their supply chain with their overall operations strategy. In SCOR terms, this is where the process can be "configured-to-order". Leagility bases the configuration on eliminating waste. Lean also can seek waste in all of the elements at the third level of SCOR, which is the "Process Element Level". This level evaluates process element definitions, information inputs and outputs, and system capabilities, in addition to other aspects. These activities are analogous to identifying value and developing the value stream map. Therefore, the application of lean at this stage of SCOR is a logical choice due to the similarity of activities. Elements of waste management such as internal controls, value proposition and continuous improvement are therefore addressed.

\subsection{Conceptual Framework}

The primary variables in this study are categorized as either independent or dependent variable. As explained by Creswell and Poth, independent variables are also termed as predictor variables due to their prediction of the amount of variation occurring in another variable [47]. Conversely, dependent variable, which is also known as criterion variables are those that are either influenced or changed by another variable. The dependent variable is the one that the researcher aims at explaining. Consequently, this study aimed to establish the influence of supply chain responsiveness and waste management on the performance of humanitarian aid organizations in Kenya. 


\section{Supply Chain Responsiveness}

- Supply chain velocity

- Supply chain reactivity

- Supply chain visibility

\section{Waste Management}

- Internal controls

- Value proposition

- Continuous improvement

\section{Independent Variables}

Performance of Humanitarian Aid Organizations

- Financial Resource utilization

- Number of Beneficiaries

- Funds raised upon financial appeals

\section{Dependent Variable}

Figure 1. Conceptual Framework.

\section{Methodology}

A survey research design was employed for this study. This research design is appropriate where large population geographically spread is involved which was the case in this study. The design enabled the study to apply both qualitative and quantitative research approaches as observed by Rahi [48] that the two approaches reinforces each other. This study was guided by a positivism research philosophy, which is part of epistemological viewpoint. The target population of this study was 330 humanitarian aid organizations carrying out their operations in Kenya as derived from the NGO Coordination Board of Kenya. This study was a census examining the entire population [49], supply chain managers in this case, which have a particular set of characteristics such as specific experience, knowledge, skills or exposure to an event. Questionnaires were used to obtain primary data for the study. The questionnaires contained structured and semistructured questions that captured the various variables of the study. The questionnaires were hand delivered by research assistants to the respondents using drop and pick technique. A pilot study was conducted from thirty-three selected NGOs in Nairobi City County. This is in line with In that the number in the pre-test should be about $1 \%$ to $10 \%$ of the target population [50]. Concerning the qualitative aspects of the study (open-ended questions), the authenticity of the findings was considered primal thus the researcher hoped that respondents would be truthful by avoiding giving distorted accounts of events surrounding supply chain leagility.

With the study being quantitative and qualitative in nature, both descriptive statistics and inferential statistics was employed. The study adopted inferential data analysis in order to enable it make suppositions that extend beyond the immediate data alone to infer from the sample data about the whole population [51]. The study used SPSS version 24 to facilitate the analysis of data. Inferential data analysis was done using Pearson correlation coefficient and regression analysis. Data was also analyzed using descriptive statistics; measures of central tendency, measures of dispersion and measures of symmetry and inferential statistics. Linear regression analysis revealed the correlation and strength of the relationship between both independent and dependent variables. Analysis of Variance also sought to test the goodness of fit of the regression models and finally to test the hypothesis of the regression models. Data collected from open-ended questions was analyzed qualitatively through content analysis. The information was presented using a combination of statistical techniques and graphical techniques. Trend analysis, was used to spot a pattern on the sub-constructs of performance of humanitarian aid organizations in the past five years. The hypothesis was tested by running an Ordinary Least Square regression model for the combined sub-constructs of each independent variable against the combined measures of the dependent variable. The acceptance/rejection criteria was that, if the P-value is greater than 0.05 , the study fails to reject the $\mathrm{H}_{0}$ but if $\mathrm{P}$ value is less than 0.05 , the $\mathrm{H}_{0}$ is rejected.

\section{Research Findings and Discussions}

The researcher distributed 330 questionnaires from which, 290 were filled and returned, an $87.88 \%$ response rate. This was a perfect representation and enough to make generalizations of the study findings. This response rate conforms to Ebert, Huibers, Christensen and Christensen affirmation that a $50 \%$ response rate is sufficient for analysis; a rate of $60 \%$ is good and that of above $70 \%$ is exceptional [52]. This praiseworthy degree of response was achieved with efforts by the researcher, who made constant visits and 
followed up to get the questionnaires filled. The unsuccessful response rate was $12.12 \%$.

\subsection{Pilot Study Results}

The study carried out a pilot test to establish the instrument reliability. The participants in the pilot test were not included in the actual study. Table 2 shows the outcome of the reliability of the questionnaire as derived from the pilot study.
The coefficients presented in Table 2 showed that supply chain responsiveness (0.729), waste management (0.719) and the dependent variable $(0.933)$ were reliable in all the measurement scales used having attained the recommended reliability level of 0.7 . This indicates that the scales in question had a high degree of internal consistency among the measurement items.

Table 1. Hypothesis Testing.

\begin{tabular}{|c|c|c|}
\hline Hypotheses & Hypotheses Test & Regression Model \\
\hline $\begin{array}{l}\text { Hypothesis } 1 \text { : } \\
\mathrm{H}_{0} \text { : Supply chain responsiveness does not significantly } \\
\text { influence the performance of humanitarian aid } \\
\text { organizations in Kenya }\end{array}$ & $\begin{array}{l}H_{0}: \beta_{1}=0 \\
\text { Vs } \\
H_{1}: \beta_{1} \neq 0 \\
\text { Reject } \mathrm{H}_{0} \text { if } p<0.05, \text { otherwise fail } \\
\text { to reject the } \mathrm{H}_{0}\end{array}$ & $\begin{array}{l}Y=\beta_{0}+\beta_{1} X_{1}+\varepsilon \text { Where: } \\
Y=\text { Performance of Humanitarian Aid Organizations } \\
\beta_{0}=\text { Constant (Coefficient of intercept) } \\
\beta_{1}=\text { Regression coefficient of } X_{1} \\
X_{1}=\text { Supply Chain Responsiveness } \\
\varepsilon=\text { Error Term }\end{array}$ \\
\hline $\begin{array}{l}\text { Hypothesis 2: } \\
\mathrm{H}_{0} \text { : Waste Management does not significantly } \\
\text { influence the performance of humanitarian aid } \\
\text { organizations in Kenya }\end{array}$ & $\begin{array}{l}H_{0}: \beta_{3}=0 \\
\text { Vs } \\
H_{1}: \beta_{3} \neq 0 \\
\text { Reject } \mathrm{H}_{0} \text { if } p<0.05 \text {, otherwise fail } \\
\text { to reject the } \mathrm{H}_{0}\end{array}$ & $\begin{array}{l}Y=\beta_{0}+\beta_{3} X_{3}+\varepsilon \text { Where: } \\
Y=\text { performance of humanitarian aid organizations } \\
\beta_{0}=\text { Constant (Coefficient of intercept) } \\
\beta_{3}=\text { Regression coefficient of } X_{3} \\
X_{3}=\text { Waste Management } \\
\varepsilon=\text { Error Term }\end{array}$ \\
\hline
\end{tabular}

Table 2. Pilot Study Reliability Statistics.

\begin{tabular}{llll}
\hline Variables & No of items & Cronbach Alpha & Comment \\
\hline Supply Chain Responsiveness & 7 & 0.729 & Accepted \\
Waste Management & 8 & 0.719 & Accepted \\
Performance of HAOs & 15 & 0.933 & Accepted \\
\hline
\end{tabular}

\subsection{Descriptive Analysis of the Study Variables}

Descriptive analysis was used to describe the basic features of the data in the study providing a summary about the sample and the measure thus helping in simplifying massive amounts of data in a sensible and convenient style. It expressed the variables in frequencies, percentages, means and standard deviation. The study analyzed descriptive statistics for all the study variables.

\subsubsection{Supply Chain Responsiveness}

The study sought to examine the influence of supply chain responsiveness on performance of humanitarian aid organizations in Kenya. This objective was measured using the following indicators: supply chain velocity, supply chain reactivity and supply chain visibility in the opinion statements given. Respondents were asked to indicate the extent to which supply chain responsiveness influenced performance of humanitarian aid organizations in Kenya. This was based on a likert scale of not at all, small extent, moderate, large extent and very large extent. Therefore, in this study, a scale of not at all and small extent implied disagree while large and very large extent implied agreement. The results were expressed as percentages, mean and standard deviation as indicated in Table 3 below.

Table 3. Descriptive Analysis of Supply Chain Responsiveness.

\begin{tabular}{|c|c|c|c|c|c|c|c|}
\hline Statements on Supply Chain Responsiveness & $\begin{array}{l}1 \\
\%\end{array}$ & $\begin{array}{l}2 \\
\%\end{array}$ & $\begin{array}{l}3 \\
\%\end{array}$ & $\begin{array}{l}4 \\
\%\end{array}$ & $\begin{array}{l}5 \\
\%\end{array}$ & Mean & Std Dev \\
\hline $\begin{array}{l}\text { Our supply chain evaluates, considers and covers needs quickly by providing basic } \\
\text { essentials to alleviate suffering people. }\end{array}$ & 0 & 0 & 24.1 & 51.7 & 24.1 & 4.00 & 0.696 \\
\hline $\begin{array}{l}\text { The supply chain has an element of visibility enabling the view of the movements } \\
\text { along the supply chain, including identity, location and status of transit together with } \\
\text { planned and actual dates and times for the events }\end{array}$ & 0 & 0 & 20.7 & 55.2 & 24.1 & 4.03 & 0.670 \\
\hline Leagility enables reliability of supply chains & 0 & 0 & 20.7 & 48.3 & 31 & 4.10 & 0.713 \\
\hline $\begin{array}{l}\text { The ability of humanitarian organizations to respond quickly to emergencies might be } \\
\text { challenging due to issues of resources, funding and lack of information }\end{array}$ & 0 & 0 & 3.4 & 51.7 & 44.8 & 4.41 & 0.559 \\
\hline $\begin{array}{l}\text { A guarantee of the humanitarian supply chain to quickly deliver is a real selling point } \\
\text { if that order arrives quickly, accurately and complete otherwise its termed as waste. }\end{array}$ & 0 & 0 & 13.8 & 51.7 & 34.5 & 4.21 & 0.664 \\
\hline $\begin{array}{l}\text { Our organization has a close partnership with suppliers that enables delivery of } \\
\text { requested supplies within the requested time and place especially when handling a } \\
\text { disaster or an emergency }\end{array}$ & 0 & 0 & 3.4 & 41.4 & 55.2 & 4.52 & 0.565 \\
\hline $\begin{array}{l}\text { Our supply chain has high degree of flexibility in terms of assembling and } \\
\text { transportation structure to meet the needs of suffering people }\end{array}$ & 0 & 0 & 17.2 & 44.8 & 37.9 & 4.21 & 0.715 \\
\hline
\end{tabular}

Key: 1-Not at all; 2-Small Extent; 3-Moderate Extent, 4-Large Extent and 5- Very Large Extent 
Majority of the respondents $(75.8 \%)$ agreed that humanitarian supply chains evaluate, consider and covers needs quickly by providing basic essentials to alleviate suffering of vulnerable people while $24.1 \%$ indicated moderate extent. Large number of respondents $(79.3 \%)$ agreed that their supply chain has an element of visibility enabling the view of the movements along the supply chain, including identity, location and status of transit together with planned and actual dates and times for the events as $20.7 \%$ moderately agreed. Elsewhere, $79.3 \%$ of the respondents agreed that leagility enables reliability of humanitarian supply chains while $20.7 \%$ moderately agreed that reliability is enabled by leagility design of the supply chains. The ability of humanitarian aid organizations to respond quickly to emergencies might be challenging due to issues of resources, funding and lack of information as indicated by $96.5 \%$ of the respondents who agreed and $3.4 \%$ of the moderate responses. Majority of the respondents (86.2\%) agreed that, a guarantee of the humanitarian supply chains to quickly deliver is a real selling point if that order arrives quickly, accurately and complete otherwise it is termed as waste while $13.8 \%$ moderately agreed.

Respondents were asked to indicate whether humanitarian aid organizations had a close partnership with suppliers that enables delivery of requested supplies within the requested time and place especially when handling a disaster or an emergency, $96.6 \%$ and $3.4 \%$ agreed and moderately agreed respectively to the statement. Lastly, majority of the respondents $(82.7 \%)$ agreed that supply chain has high degree of flexibility in terms of assembling and transportation structure to meet the needs of suffering people as $17.2 \%$ indicated moderate.

In general, the findings in Table 3 found out that humanitarian aid organizations in Kenya have supply chains that are designed to be responsive to the needs of vulnerable populations. The humanitarian supply chain are designed to evaluate, consider and cover needs quickly while enabling a view of the movements along the supply chain. Further to increase the element of supply chain velocity and reactivity, humanitarian aid organizations have established close relationships with suppliers in the effort to improve responsiveness. The humanitarian supply chains are also designed to be flexible to meet the needs of vulnerable people in aspects of transportation, assembling and dispatch. However, the ability of humanitarian aid organizations to respond quickly to emergencies and disasters is a challenging task influenced by the various challenges facing humanitarian supply chains such as lack of information, insufficient resources and poor funding. This means that despite the supply chains being designed to be responsive to emergencies, there is still an element of sluggishness in most humanitarian supply chains in Kenya resultant from the challenges faced. This shows lack of preparedness by humanitarian aid organizations in responding to emergencies and disasters. Preparedness entails all the activities undertaken before a disaster occurs that enhance the readiness of humanitarian organizations and the society to counter the emergency. Preparedness measures are crucial as they minimize the time spent in undertaking the immediate response and increase the odds of quick recovery. During the preparation phase, hazards/risks are acknowledged and strategies designated to address response and recovery necessities. The findings of this study concurred with Rodríguez-Espíndola, Chowdhury, Beltagui and Albores study that established the humanitarian supply chain management challenges as delayed delivery of the appropriate products, faulty information integration and uncertainty in demand among others [53].

\subsubsection{Waste Management}

The study sought to determine the influence of waste management on performance of humanitarian aid organizations in Kenya. This objective was measured using the following indicators: internal controls, value proposition and continuous improvement in the opinion statements given. Respondents were required to indicate the extent to which waste management influenced performance of humanitarian aid organizations in Kenya. This was on a likert scale of not at all, small extent, moderate, large extent and very large extent. Therefore, in this study the scale of Not at all and small extent meant disagree while large and very large extent meant agreed. The results were expressed as percentages, mean and standard deviation as shown in Table 4 below.

Table 4. Descriptive Analysis of Waste Management.

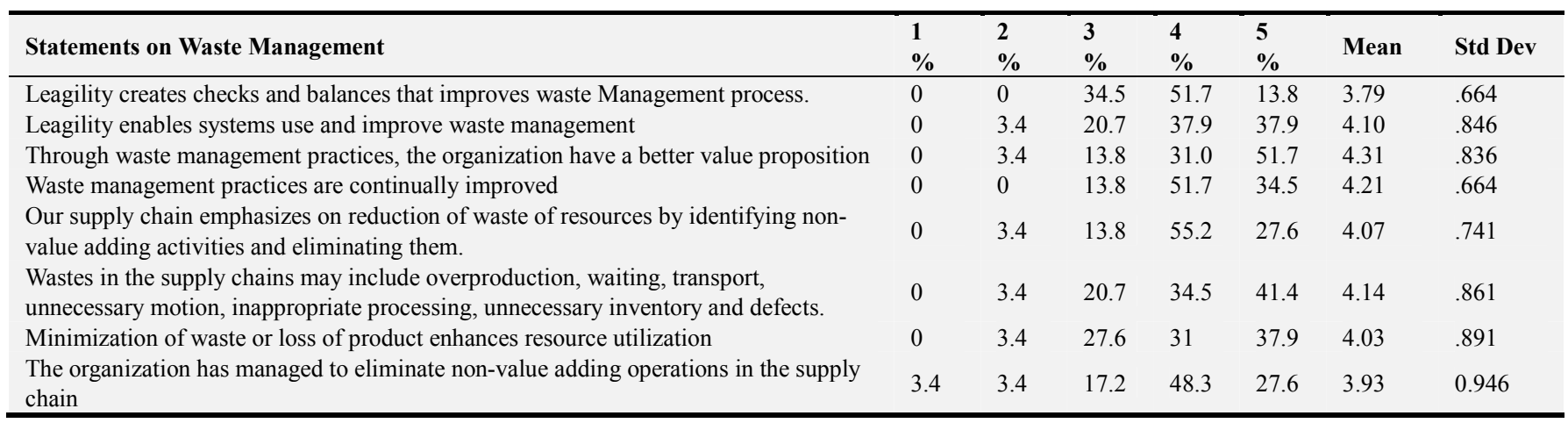

Key: 1-Not at all; 2-Small Extent; 3-Moderate Extent, 4-Large Extent and 5- Very Large Extent 
Majority of the respondents (65.5\%) agreed that leagility creates checks and balances that improves waste management process in supply chains as $34.5 \%$ moderately agreed that leagility design of supply chains provides for checks and balances. A large number $(75.8 \%)$ of respondents agreed that leagility enables systems use and improve waste management. $20.7 \%$ moderately agreed as $3.4 \%$ of the respondents disagreed that leagility enables systems use and improvement of waste management. Respondents agreed $(82.7 \%)$ that through waste management practices humanitarian aid organizations have better value propositions. $3.4 \%$ of the respondents disagreed as $13.8 \%$ moderately alluded to the statement. The practice of waste management in humanitarian aid organizations is continuous improved as indicated by $86.2 \%$ and $13.8 \%$ of the respondents who agreed and moderately agreed respectively.

Majority of the respondents $(82.8 \%)$ agreed that humanitarian supply chains emphasize on reduction of wastage of resources by identifying non-value adding activities and eliminating them. 13.8\% moderate responded while $3.4 \%$ disagreed on the emphasize. Respondents were asked to respond on the various types of wastes in humanitarian supply chains and $75.9 \%$ of the respondents agreed that overproduction, waiting, transport, unnecessary motion, inappropriate processing, unnecessary inventory and defects are the common types of waste in supply chains as $20.7 \%$ moderately agreed and $3.4 \%$ disagreed with the assertion. A large number of respondents (68.9\%) also agreed that minimization of wastes enhances resource utilization. Lastly, most humanitarian aid organizations (75.9\%) had managed to eliminate non-value adding operations in their supply chains as indicated in the findings as $17.2 \%$ moderately responded. Still $6.8 \%$ of the organizations were yet to eliminate non-value adding operations in their humanitarian supply chains.

Based on the study findings in Table 4, leagility is an essential design of waste management in humanitarian supply chains. Leagility design creates checks \& balances and enables systems use improving waste management. Waste management is a continuous exercise in humanitarian aid organizations involving identification of non-value adding activities in the supply chains and eliminating them. Majority of the organizations had managed to eliminate the non-value adding operations in their supply chains but still some humanitarian aid organizations were yet to. Overproduction, waiting, transport, unnecessary motions, inappropriate processing, unnecessary inventories \&defects, theft, misappropriation, poor tracking and control as well as product deterioration were identified as the common types of wastes in humanitarian supply chains. Minimization of such wastages enhances resource utilizations in the organizations. Most humanitarian supplies fall into the relief items category that face specific challenges related to in-kind donations ranging from storage and transportation bottlenecks that bring about inefficiency.

The findings of this study agree with Iyengar and Bharathi
[54] study of analysis of lean, agile, and leagile supply chains that waste management is an important aspect of leagility supply chain. To eliminate wastes from all the elements of the supply chain calls for continuous improvement processes. Hassani, Ceauşu and Iordache [55] on the other hand in their study on lean and agile model implementation for managing the supply chain found that volatile and unpredictable environments demand supply chains that minimize waste and ensure flexibility, as was the case in the findings of this study.

\subsection{Qualitative Analysis}

Thematically, recurrent themes were drawn from qualitative responses received from the supply chain managers. As many potential themes as possible were manually coded for purposes of establishing patterns.

\subsubsection{Supply Chain Responsiveness}

Exploration of the views of supply chain managers on supply chain responsiveness was conducted using three items on research instrument. First, the various disasters that disrupt communities triggering the need for supply chain responsiveness. Secondly, the strategies humanitarian aid organizations adopt to make their supply chains more responsive. Lastly, respondents were asked to identify the driving forces making humanitarian aid organizations design their supply chains to be responsive to societal needs.

The study sought to determine the various disasters and situations triggering the need for supply chains to be responsive by disrupting communities at large in Kenya. The findings indicated that Kenya has been subjected to various disasters, which are classified on basis of origin and cause as either manmade (anthropogenic) or natural in nature. Commonly identified natural disasters included disease outbreaks, plagues/invasions, floods, landslides/mudslides, droughts and famine. Additionally, though utterly devastating but occurring less frequently in Kenya, other natural disasters (geographic in nature) include earthquakes and volcanic eruptions. Manmade disasters, commonly known as anthropogenic disasters because they occur from human activities, can be categorized into technological, sociological and transportation disasters. Common manmade disasters identified included structural/buildings collapse, chemical leaks, spillovers, manmade fires, terrorist activities, human conflicts, traffic accidents and politically instigated violence.

Four themes commonly emerged from the participating supply chain managers concerning the strategies adopted in increasing supply chain responsiveness. Modularity emerged as a strategy to increase supply chain responsiveness in humanitarian aid organizations. Modularization in supply chain management refers to division of a greater whole to interchangeable parts that fit together seamlessly and together in many different combinations and permutations make many different wholes [56].

Another strategy commonly identified from the views of supply chain managers to increase responsiveness in humanitarian supply chains is shortened lead-times. 
Analyzing lead times is of high significance especially in supply of critical items and time values are more vital in humanitarian relief. The sensitiveness of the time factor is the need to deliver goods in time so they can be availed to the victims at the right time in the perfect condition. This could be achieved by utilization of local sources of supply or through having strategic suppliers ready to deliver when need arises.

Transport and capacity planning emerged as a strategy used by humanitarian aid organizations to respond quickly to disasters. Unidentified circumstances, and at times, ruined infrastructure, make it challenging to plan for transportation and volume capability. Transportation is a significant link between agencies, facilitating the flow of goods among them [57]. The postponement strategy effectively reduces inventory obsolescence and eradicates the risk and uncertainty costs related to having undesirable products, but it requires an integrated and agile supply chain to be able to create and proliferate the latest demand forecasts across the supply chain to produce or allocate the appropriate products for their clients. The driving forces making humanitarian aid organizations to design responsive supply chains emerged as the need to rescue lives, pressure from donors and the increased number of disasters and emergencies in the contemporary period.

\subsubsection{Waste Management}

An examination of waste management practices in humanitarian aid organizations was conducted using openended questions to the supply chain managers. Two items were used seeking the various forms of wastes in humanitarian supply chains and the mechanisms humanitarian aid organizations employ to minimize wastes in their supply chains. There is a lot of wastage associated with humanitarian aid because the development of incessant supply chains has been ignored.

Forms of wastes in humanitarian supply chains emerging from the views of supply chain managers include corruption and diversion of funds. With the circumstances existing in most donor-funded humanitarian aid organizations, funds allocated for emergency response are prone to corruption as an external factor. Other ways of diversion of funds identified were sale of goods intended for relief and distribution of relief items to people to whom the aid is not intended in exchange for payment. Delaying the spending of emergency funds on the purpose they are meant for and investing them in the meantime. Those involved then pocket the earned profits. Certainly, the findings of this study support Bader [58] findings that diversion of aid funds largely reduces the quantity, quality and appropriateness of assistance for the needy and instead serve the interests of hidden target groups to whom the aid was never meant. Concisely, disasters and pandemics provide a smokescreen for dubious transactions for personal benefit with no or little scrutiny. This explains the increase in money-minting schemes by disasterpreneurs.

Mechanisms of addressing supply chain wastage in relief operations identified included the eradication of import and tax fees. Furthermore, punishments were imposed for misuse of services, cancellations had to be done the soonest possible, and a binding clarification made. It was further declared that communication was to be made any time a service needed to be made. This is to avoid concentrating aid in some places while leaving others out. Checks and balances also emerged to be a control against theft and use of goods made for vulnerable people for private gains. Other internal control mechanisms include audits boosting effective resource utilizations. To control charity fraud, charity-monitoring organizations played a crucial role in eradicating fraud and availing to donors, information about humanitarians.

\subsection{Confirmatory Factor Analysis}

Factor analysis as a dimension reduction technique was conducted to retain the smallest number of factors that had the highest influence in terms of the total variance explained. Factor analysis was conducted using Principal Component method approach. The extraction of the factors followed the Kaiser Criterion where an Eigen value of 1 or more indicates a unique factor. Prior to conducting factor analysis, KaiserMeyer-Olkin (KMO) criterion was used as a measure for sampling adequacy to determine whether each of the variables was suitable for factor analysis. KMO values greater than 0.5 indicates that the sample is adequate for factor analysis to be applicable. The results for KMO test are as shown in Table 5 below.

Table 5. KMO Test for the Variables.

\begin{tabular}{ll}
\hline Variables & Kaiser-Meyer-Olkin (KMO) Measure of Sampling Adequacy \\
\hline Supply chain responsiveness & 0.681 \\
Waste management & 0.648 \\
Performance of Humanitarian aid organizations & 0.505 \\
\hline
\end{tabular}

From the results in Table 5, the KMO values for the variables were as follows: supply chain responsiveness $(0.681>0.5)$, waste management $(0.648>0.5)$ and the KMO value for performance of humanitarian aid organizations was $0.505>0.5$. Therefore, all the three variables were considered adequate for application of factor analysis.

\subsubsection{Factor Analysis for Supply Chain Responsiveness}

Principal Components Analysis (PCA) was used to extract maximum variance from the data set with each component. Based on Kaiser's criterion, the first and the second principal components out of seven principal components were extracted. The first two principal components were able to explain $56.3 \%$ of the resulting variance in the data on supply 
chain responsiveness. The two extracted principal shown in Table 6. components have eigenvalues greater than 1.0. The result is

Table 6. Total Variance Explained.

\begin{tabular}{cclllll}
\hline \multicolumn{2}{c}{ Component } & Initial Eigenvalues & & & \multicolumn{2}{c}{ Extraction Sums of Squared Loadings } \\
\hline & Total & \% of Variance & Cumulative \% & Total & \% of Variance & Cumulative \% \\
\hline 1 & 2.758 & 39.406 & 39.406 & 2.758 & 39.406 & 39.406 \\
2 & 1.183 & 16.898 & 56.304 & 1.183 & 16.898 & \\
3 & .957 & 13.665 & 69.969 & & & \\
4 & .790 & 11.292 & 81.260 & & & \\
5 & .502 & 7.171 & 88.431 & & & \\
6 & .467 & 6.674 & 95.106 & & & \\
7 & .343 & 4.894 & 100.000 & & & \\
\hline
\end{tabular}

Table 7 presents the results of the values of the factor loading of each of the constructs under supply chain responsiveness on the extracted principal components. The item with absolute factor loadings greater than 0.5 , on either of the principal components extracted is retained for further analysis [59]. In this study, all the items under supply chain responsiveness had a factor loading of greater than 0.5. Therefore, the study considered all the seven supply chain responsiveness statements.

Table 7. Component Matrix.

\begin{tabular}{lll}
\hline & Component & \\
\cline { 2 - 3 } & $\mathbf{1}$ & $\mathbf{2}$ \\
\hline SCR1 & .475 & .739 \\
SCR2 & .627 & -.046 \\
SCR3 & .651 & .309 \\
SCR4 & .600 & .341 \\
SCR5 & .728 & -.282 \\
SCR6 & .662 & -.341 \\
SCR7 & .623 & -.478 \\
\hline
\end{tabular}

\subsubsection{Factor Analysis for Waste Management}

Table 8 shows the total variance explained by the components in data relating to waste management. Based on Kaiser's criterion, the first, the second and the third principal components out of eight principal components, were extracted. The first three principal components were able to explain $73.55 \%$ of the total variance in the data on waste management.

Table 8. Total Variance Explained.

\begin{tabular}{llllll}
\hline \multirow{2}{*}{ Component } & \multicolumn{3}{c}{ Initial Eigenvalues } & \multicolumn{2}{c}{ Extraction Sums of Squared Loadings } \\
\cline { 2 - 6 } & Total & \% of Variance & Cumulative \% & Total & \% of Variance \\
\hline 1 & 2.984 & 37.297 & 37.297 & 2.984 & 37.297 \\
2 & 1.593 & 19.912 & 57.209 & 1.593 & 19.912 \\
3 & 1.307 & 16.338 & 73.547 & 1.307 & \\
4 & .656 & 8.200 & 81.747 & \\
5 & .551 & 6.893 & 88.640 & \\
6 & .434 & 5.429 & 94.068 & \\
7 & .263 & 3.284 & 97.353 & \\
8 & .212 & 2.647 & 100.000 & \\
\hline
\end{tabular}

The loadings on the three factors extracted by the principal component method are indicated in Table 9. All the eight items under waste management had a factor loading greater than 0.5 on either of the three factors hence all the statements under this construct were considered for analysis.

Table 9. Component Matrix.

\begin{tabular}{llll}
\hline & Component & & \\
\cline { 2 - 4 } & $\mathbf{1}$ & $\mathbf{2}$ & $\mathbf{3}$ \\
\hline WM1 & .222 & -.175 & .850 \\
WM2 & .668 & .099 & .337 \\
WM3 & .604 & .366 & .441 \\
WM4 & .081 & .840 & -.165 \\
WM5 & .713 & .400 & -.150 \\
WM6 & .701 & -.482 & -.100 \\
WM7 & .666 & -.552 & -.276 \\
WM8 & .821 & .127 & -.373 \\
\hline
\end{tabular}




\subsubsection{Factor Analysis for Performance of Humanitarian Aid Organizations}

The results in Table 10 shows the total variance explained by the components in data relating to the performance of
HAOs. The Principal Component method extracted one factor out of the possible 3 factors, based on Kaiser's criterion. The one factor explained about $65.49 \%$ of the total variance in the performance data.

Table 10. Total Variance Explained.

\begin{tabular}{lllllll}
\hline \multirow{2}{*}{ Component } & \multicolumn{2}{l}{ Initial Eigenvalues } & & \multicolumn{3}{l}{ Extraction Sums of Squared Loadings } \\
\cline { 2 - 7 } & Total & \% of Variance & Cumulative \% & Total & \% of Variance & Cumulative \% \\
\hline 1 & 1.965 & 65.485 & 65.485 & 1.965 & 65.485 & \\
2 & .979 & 32.635 & 98.120 & & & \\
3 & .056 & 1.880 & 100.000 & & & \\
\hline
\end{tabular}

The component matrix result in Table 11 shows that appeal coverage, number of beneficiaries and financial resource utilization had loadings of $0.980,0.205$ and 0.980 on the first factor, respectively. Consequently, appeal coverage and financial resource utilization were considered for analysis as they loaded more than 0.5 on the extracted factor.

Table 11. Component Matrix.

\begin{tabular}{ll}
\hline & Component \\
\cline { 2 - 2 } & $\mathbf{1}$ \\
\hline Appeal coverage & .981 \\
Number of beneficiaries & .205 \\
Financial resource utilization & .980 \\
\hline
\end{tabular}

\subsection{Correlation of Study Variables}

Table 12 illustrates the correlation matrix between the independent variables. Correlation is essentially a tool for determining how a collection of variables relate [60] thereby facilitating the testing for multicollinearity. That the correlation values are not close to 1 or -1 is an indication that the factors are sufficiently different measures of separate variables [60]. It also implies that the variables are not multicollinear. When there is no multicollinearity, the study is able to utilize all the independent variables.

Table 12. Results for Correlation of Study Variables.

\begin{tabular}{|c|c|c|c|c|}
\hline & & Performance of HAOs & SCR & WM \\
\hline \multirow{3}{*}{ Performance of HAOs } & Pearson Correlation & 1 & & \\
\hline & Sig. (2-tailed) & & & \\
\hline & $\mathrm{N}$ & 290 & & \\
\hline \multirow{3}{*}{ Supply Chain Responsiveness } & Pearson Correlation & $.765^{* *}$ & 1 & \\
\hline & Sig. (2-tailed) & 0.000 & & \\
\hline & $\mathrm{N}$ & 290 & 290 & \\
\hline \multirow{3}{*}{ Waste Management } & Pearson Correlation & $0.661^{* *}$ & 0.31 & 1 \\
\hline & Sig. (2-tailed) & 0.000 & 0.062 & \\
\hline & $\mathrm{N}$ & 290 & 290 & 290 \\
\hline
\end{tabular}

** Correlation is significant at the 0.01 level (2-tailed).

*. Correlation is significant at the 0.05 level (2-tailed).

Correlation coefficient ranges from -1.00 to +1.00 . The value of -1.00 signifies a perfect negative correlation whereas a value of +1.00 represents a perfect positive correlation. A value of 0.00 implies the absence of any relationship among variables being tested [61]. The results shows presence of a positive and significant relationship between supply chain responsiveness and waste management as proved by the p-value and the correlation coefficient $(\mathrm{r}=0.310, \mathrm{p}<0.05)$. Usually waste within the supply chain makes the supply chain sluggish to react and respond to societal needs. Inefficiency in activities because of failed coordination results in poor responsiveness and time wastage in the acquiring of the items needed for a particular disaster.

\subsection{Regression Analysis Results}

The research used regression analysis to establish the linear statistical relationship between independent and dependent variables of this study. The two hypotheses as stated in this study were tested using regression models.

Test of Hypothesis 1: Supply Chain Responsiveness and Performance of HAOs

A correlation analysis for the construct, supply chain responsiveness was conducted to find out how supply chain responsiveness correlated with performance of HAOs. Correlation coefficient can range from -1.00 to +1.00 . The value of -1.00 represents a perfect negative correlation whereas that of +1.00 represents a perfect positive correlation. A value of 0.00 indicates absolute absence of a relationship between variables being tested [61]. Table 13 shows that the Pearson correlation coefficient was 0.765 . These findings indicate that there is a strong positive linear relationship between supply chain responsiveness and performance of HAOs. 
Table 13. Correlation Analysis for Construct Supply Chain Responsiveness.

\begin{tabular}{llll}
\hline Variables & & Performance of HAOs & Supply Chain Responsiveness \\
\hline \multirow{3}{*}{ Performance of HAOs } & Pearson Correlation & 1 & $.765^{* *}$ \\
& Sig. (2-tailed) & & .000 \\
& $\mathrm{~N}$ & 290 & 290 \\
Supply Chain Responsiveness & Pearson Correlation & $.765^{* *}$ & 1 \\
& Sig. (2-tailed) & .000 & 290 \\
\hline
\end{tabular}

**. Correlation is significant at the 0.01 level (2-tailed).

*. Correlation is significant at the 0.05 level (2-tailed).

The researcher conducted regression analysis to examine the influence of supply chain responsiveness on the performance of HAOs. The hypothesis to test for this specific objective was:

$H_{0}$ : Supply chain responsiveness does not significantly influence the performance of humanitarian aid organizations in Kenya.

The histogram in Figure 2 indicates that the data was normally distributed. The residual describes the error in the fit of the model to the $i^{\text {th }}$ observation yi and are used to provide information about the adequacy of the fitted model. According to Wogi, Wakweya and Tesfay, analysis of the residual is frequently helpful in checking the assumption that errors are normally distributed with constant variance and in determining whether additional terms in the model would be useful [62].

The linear regression model shows $\mathrm{R}^{2}=0.585$ which means that about 58.5 percent of the total variance in the performance of HAOs in Kenya can be explained by supply chain responsiveness. The result is shown in Table 14.

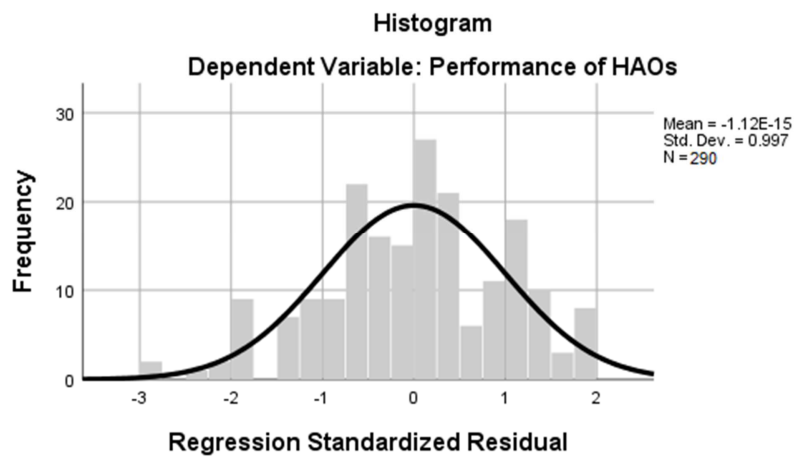

Figure 2. Histogram supply chain responsiveness on performance of HAOS.

Table 14. Model Summary of Supply Chain Responsiveness.

\begin{tabular}{lllll}
\hline Model & R & R Square & Adjusted R Square & Std. Error of the Estimate \\
\hline 1 & $.765^{\text {a }}$ & .585 & .579 & .74484 \\
a. Predictors: (Constant), Supply Chain Responsiveness & & \\
b. Dependent Variable: Performance of Humanitarian Aid Organizations & & \\
\hline
\end{tabular}

Further test on the ANOVA shows that the significance of the F-statistic $(\mathrm{p}<0.05)$ is less than 0.05 as indicated in Table 15 . This is an implication that supply chain responsiveness has a significant influence on performance of HAOs.

Table 15. ANOVA of Supply Chain Responsiveness.

\begin{tabular}{|c|c|c|c|c|c|c|}
\hline Model & & Sum of Squares & Df & Mean Square & $\mathbf{F}$ & Sig. \\
\hline \multirow{3}{*}{1} & Regression & 7.439 & 1 & 7.439 & 12.099 & $.000^{\mathrm{b}}$ \\
\hline & Residual & 177.081 & 288 & 0.615 & & \\
\hline & Total & 184.52 & 289 & & & \\
\hline $\begin{array}{l}\text { a. Depe } \\
\text { b. Predi }\end{array}$ & $\begin{array}{l}\text { ndent Variabl } \\
\text { ctors: (Consta }\end{array}$ & $\begin{array}{l}\text { of Humanitarian Ai } \\
\text { in Responsiveness }\end{array}$ & & & & \\
\hline
\end{tabular}

Presented in Table 16 are the coefficients and t-statistic of the resulting model. The constant term $\beta_{0}=5.77$, implies that if supply chain responsiveness is held constant, then there will be a positive performance of HAOs in Kenya by 5.77. The regression coefficient for supply chain responsiveness was positive and significant $\left(\beta_{1}=0.224\right.$, $\mathrm{p}<0.05$ ), with a $\mathrm{t}$-value of 3.556 . This implies that for every unit increase in supply chain responsiveness, performance of HAOs is predicted to increase by 0.224 units.

Table 16. Coefficients of Supply Chain Responsiveness.

\begin{tabular}{|c|c|c|c|c|c|c|}
\hline \multirow{2}{*}{ Model } & & \multicolumn{2}{|c|}{ Unstandardized Coefficients } & \multirow{2}{*}{$\begin{array}{l}\text { Standardized Coefficients } \\
\text { Beta }\end{array}$} & \multirow{2}{*}{$\mathbf{T}$} & \multirow{2}{*}{ Sig. } \\
\hline & & B & Std. Error & & & \\
\hline \multirow{2}{*}{1} & (Constant) & 5.770 & 0.477 & & 12.101 & 0.000 \\
\hline & Supply Chain Responsiveness & 0.224 & 0.063 & 0.765 & 3.556 & 0.000 \\
\hline
\end{tabular}


From the results in Table 13 to Table 16 above, the null hypothesis that supply chain responsiveness does not significantly influence the performance of humanitarian aid organizations in Kenya, is rejected. This result revealed that supply chain responsiveness contributes positively towards performance of HAOs in Kenya. Humanitarian organizations normally operate in unstable environments, necessitating strategies that enhance their response to risks and uncertainties in demand, supply and processes [63]. This calls for readiness, swift disposition of the needed resources, and capacity to cope proficiently in different settings. Extant research [64-66] argue that the operational performance of humanitarian supply chains relies on their ability to respond swiftly to the needs of vulnerable populations and undertake dynamic operations. For this to be possible, humanitarian supply chains must be responsive, amenable and efficient. Sharing the same view is Munyoro [67] emphasizing that proper response to the humanitarian needs in case of disasters is considered to be mitigation and satisfying the initial and vital needs of the survivors and thus must be done in the shortest time using the least amount of the resources to reduce the terrible effects of the disaster.

Test of Hypothesis 2: Waste Management and Performance of HAOs

A correlation analysis for the construct waste management was conducted to establish how waste management correlated with performance of HAOs. Table 17 shows that the Pearson correlation coefficient was 0.661 . |These findings indicate the presence of a strong positive linear relationship between waste management and performance of HAOs.

Table 17. Correlation Analysis for Construct Waste Management.

\begin{tabular}{llll}
\hline Variable & & Performance of HAOs & Waste Management \\
\hline & Pearson Correlation & 1 & $.661^{*}$ \\
Performance of HAOs & Sig. (2-tailed) & & .000 \\
& N & 290 & 290 \\
& Pearson Correlation & $.661^{* *}$ & 1 \\
Waste Management & Sig. (2-tailed) & .000 & 290 \\
& $\mathrm{~N}$ & 290 \\
\hline
\end{tabular}

**. Correlation is significant at the 0.01 level (2-tailed).

${ }^{*}$. Correlation is significant at the 0.05 level (2-tailed).

Regression analysis was conducted to determine the influence of waste management on the performance of HAOs. The hypothesis to test for this specific objective was:

$H_{0}$ : Waste management does not significantly influence the performance of humanitarian aid organizations in Kenya.

The histogram in figure 3 indicates that the data was normally distributed. The residual describes the error in the fit of the model to the $\mathrm{i}^{\text {th }}$ observation yi and are used to explain the adequacy of the fitted model. According to Wogi, Wakweya and Tesfay, analysis of the residual is frequently helpful in checking the assumption that errors are normally distributed with constant variance, and in determining whether additional terms in the model would be useful [62].

Presented in Table 18 is the model summary of regression of waste management on performance of HAOs. The results show $\mathrm{R}^{2}=0.436$ which means that about 43.6 percent of the total variation in the performance of HAOs in Kenya can be attributed to waste management.

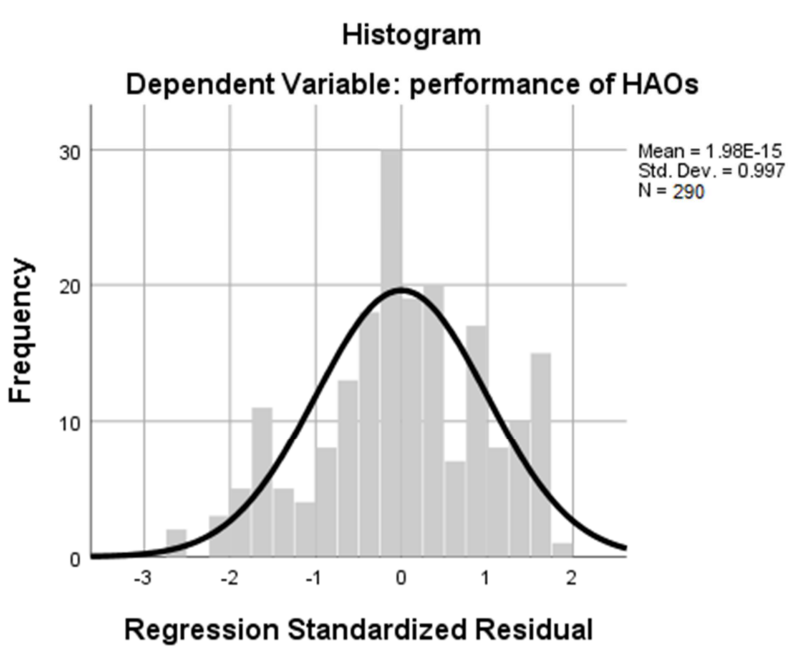

Figure 3. Histogram Waste management on performance of HAOs.

Table 18. Model Summary of Waste Management.

\begin{tabular}{lllll}
\hline Model & R & R Square & Adjusted R Square & Std. Error of the Estimate \\
\hline 1 & $.661^{\text {a }}$ & .436 & .427 & .78413 \\
\hline
\end{tabular}

a. Predictors: (Constant), Waste Management

b. Dependent Variable: Performance of Humanitarian Aid Organizations

Table 19. ANOVA of Waste Management.

\begin{tabular}{llllll}
\hline Model & & Sum of Squares & Df & Mean Square & F \\
\hline \multirow{3}{*}{1} & Regression & 19.743 & 1 & 19.743 & 35.587 \\
& Residual & 159.777 & 288 & $.000^{\mathrm{b}}$ \\
& Total & 179.520 & 289 & & \\
\hline
\end{tabular}

a. Dependent Variable: Performance of Humanitarian Aid Organizations

b. Predictors: (Constant), Waste Management 
Further test on the ANOVA shows that the regression model involving performance of HAOs as the dependent variable and waste management as the predictor, is very significant at 5\% level of significance (F-statistic $=35.587$, $\mathrm{p}<0.05$ ), as indicated in Table 19. This is an implication that waste management has a very significant influence on the performance of HAOs.

Further, Table 20 presents the coefficients and t-statistic of the resulting model. The constant term $\beta_{0}=4.490$, implies that if waste management is kept constant, then there will be a positive performance of HAOs in Kenya by 4.490. The regression coefficient for waste management was positive and significant at $5 \%$ level of significance $\left(\beta_{1}=0.547\right.$, $\mathrm{p}<0.05$ ), with a t-value of 5.965. This is interpreted to mean that for every unit increase in waste management, performance of HAOs is predicted to increase by 0.547 units.

Table 20. Coefficients of Waste Management.

\begin{tabular}{|c|c|c|c|c|c|c|}
\hline \multirow{2}{*}{ Model } & & \multicolumn{2}{|c|}{ Unstandardized Coefficients } & \multirow{2}{*}{$\begin{array}{l}\text { Standardized Coefficients } \\
\text { Beta }\end{array}$} & \multirow{2}{*}{$\mathbf{T}$} & \multirow{2}{*}{ Sig. } \\
\hline & & B & Std. Error & & & \\
\hline \multirow{2}{*}{1} & (Constant) & 4.490 & .376 & & 11.949 & .000 \\
\hline & Waste management & .547 & .092 & .661 & 5.965 & .000 \\
\hline
\end{tabular}

Dependent Variable: Performance of Humanitarian Aid Organizations

Performance of Humanitarian Aid Organizations $=4.490+0.547$ Waste Management

From the results in Table 17 to Table 20 above, the null hypothesis that waste management does not significantly influence the performance of humanitarian aid organizations in Kenya, is rejected. This result revealed that waste management contributes positively towards performance of HAOs in Kenya. The findings of this study are in line with Balle, Jones, Chaize and Fiume [68] that for organizational effectiveness and for gaining competitive advantage in cost, it is necessary for the organization to eliminate waste. In general, waste is the failure to add, or is a barrier to adding, value for the customer/beneficiary.

\subsection{Trend Analysis for Performance of Humanitarian Aid Organizations}

\subsubsection{Appeal Coverage}

The findings in Figure 4 indicate an increase in funding by humanitarian aid organizations upon financial appeals over a period of five years (2015-2019). This means that humanitarian organizations have mastered the art of soliciting funds and mobilizing resources from sources ranging from individual donors, foundations, corporations, governments and other alternatives. As advised by Ye, Y and Yan, failure of humanitarian organizations to achieve efficiency may not only result in loss of lives, but also in the loss of vital donor funds. Though the funding has increased over the last five years, the amount is still not sufficient for humanitarian operations [69].

Roddy, Strange and Taithe [70] cautioned humanitarians that are in constant pursuit of new opportunities to raise funds to not to fall prey to fraudsters. Humanitarian aid organizations should not solicit from the public in the name of charity using illusive methods or use the funds obtained for purposes not intended by the donors. This is termed as charity fraud regarded as a repulsive kind of dishonest business practice as it manipulates philanthropic persons who decide to give donations in the belief that they are helping the needy. The graphical presentation of the average funds realized from appeals by HAOs in the year 2015 through 2019 reveals an increasing trend as shown in Figure 4.

\subsubsection{Number of Beneficiaries from Humanitarian Aid Operations}

This trend analysis shows an increase in the number of beneficiaries in the 2015-2019 period. The graphical presentation of the number of beneficiaries from humanitarian operations in the year 2015 through 2019 reveals an increasing trend as shown in Figure 5. This is because of the increasing number of disasters affecting societies in the contemporary period ranging from manmade to natural disasters. Disasters are common in Kenya and the regularity of occurrence and numbers of victims increasing every day. The increase in numbers of victims is primarily a result out of the growing populations with human activities contributing to the frequency of occurrence. Furthermore, the increase in the number of beneficiaries is attributed to the effectiveness in handling humanitarian operations by the humanitarian aid organizations.

\subsubsection{Financial Resource Utilization}

Trend analysis was done for financial resource utilization to show how humanitarian organizations use funds raised upon financial appeals. The findings of this study indicate that over the years (2015-2019 period) humanitarian aid organizations have received increasing donor funding upon financial appeals and subsequently efficiently utilized the funding for running humanitarian operations. This is because in recent years, humanitarians have been under immense pressure from donors promising a lot but demanding for proof that they are meeting their objectives in the most efficient and effective way [71]. Due to this, humanitarian organizations have to give interest to result as well, be accountable and transparent in their operations. More pressure on resource utilization and performance is a result of increased natural and conflict compelled disasters, which demand more simultaneous relief operations around the world.

The proportion of funds spent on humanitarian operations dropped significantly between the years 2017 (41.16\%) and $2018(40.45 \%)$ as indicated in Figure 7 . This is attributed to 
the political environment in Kenya. The need for accountability has driven donors to demand for competitive procurement of goods by humanitarian organizations and that the goods meet the proper standards. The donors now require humanitarian aid organizations to continuously find new innovative ways of minimizing costs of running while exhibiting better performance.

Table 21. Descriptive Statistics for the Total Expenses Incurred in HA Operations.

\begin{tabular}{ll}
\hline Year & Proportion of Amount Spent on Humanitarian Operations (\%) \\
\hline 2015 & 63.86 \\
2016 & 67.41 \\
2017 & 41.16 \\
2018 & 40.45 \\
2019 & 70.50 \\
\hline
\end{tabular}

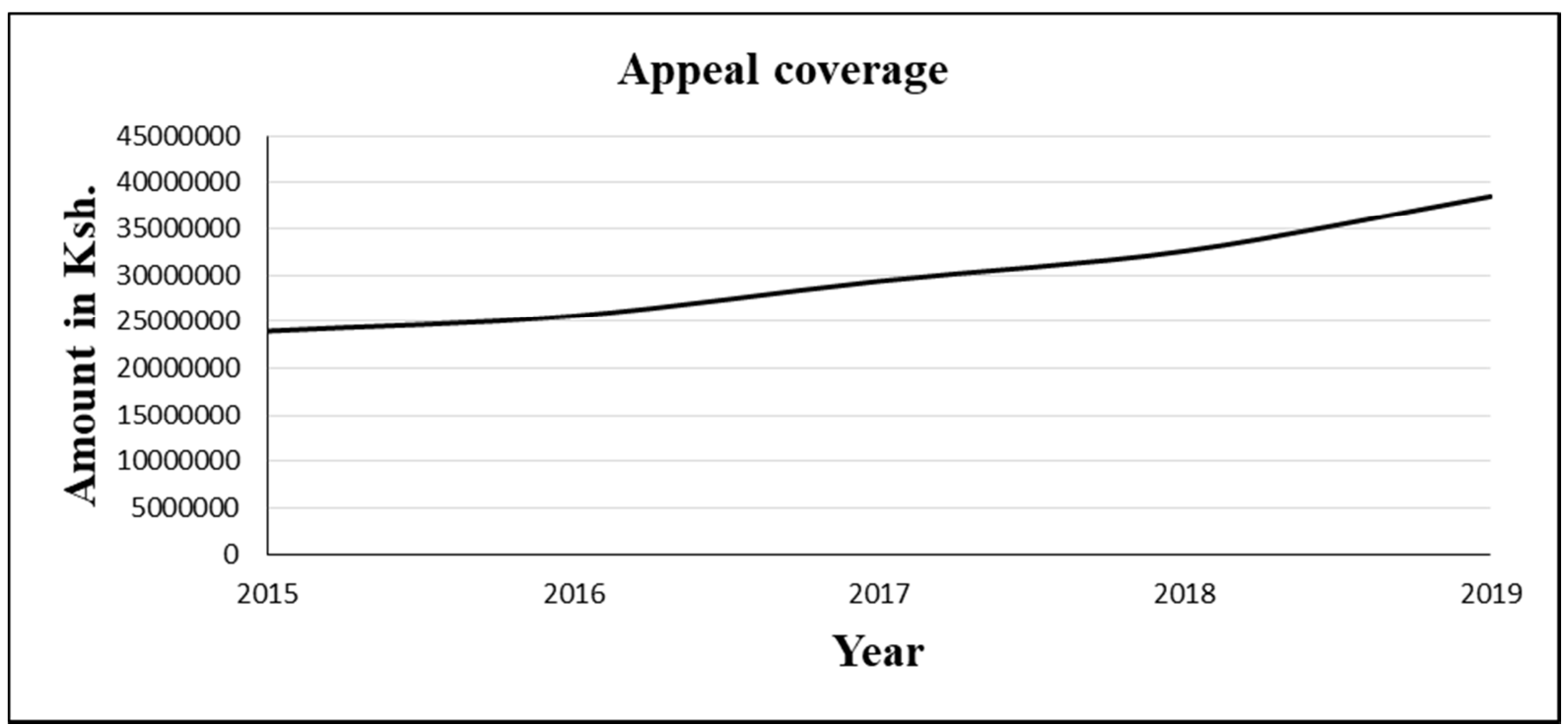

Figure 4. Average Funds Raised In Appeal Coverage from 2015 to 2019.

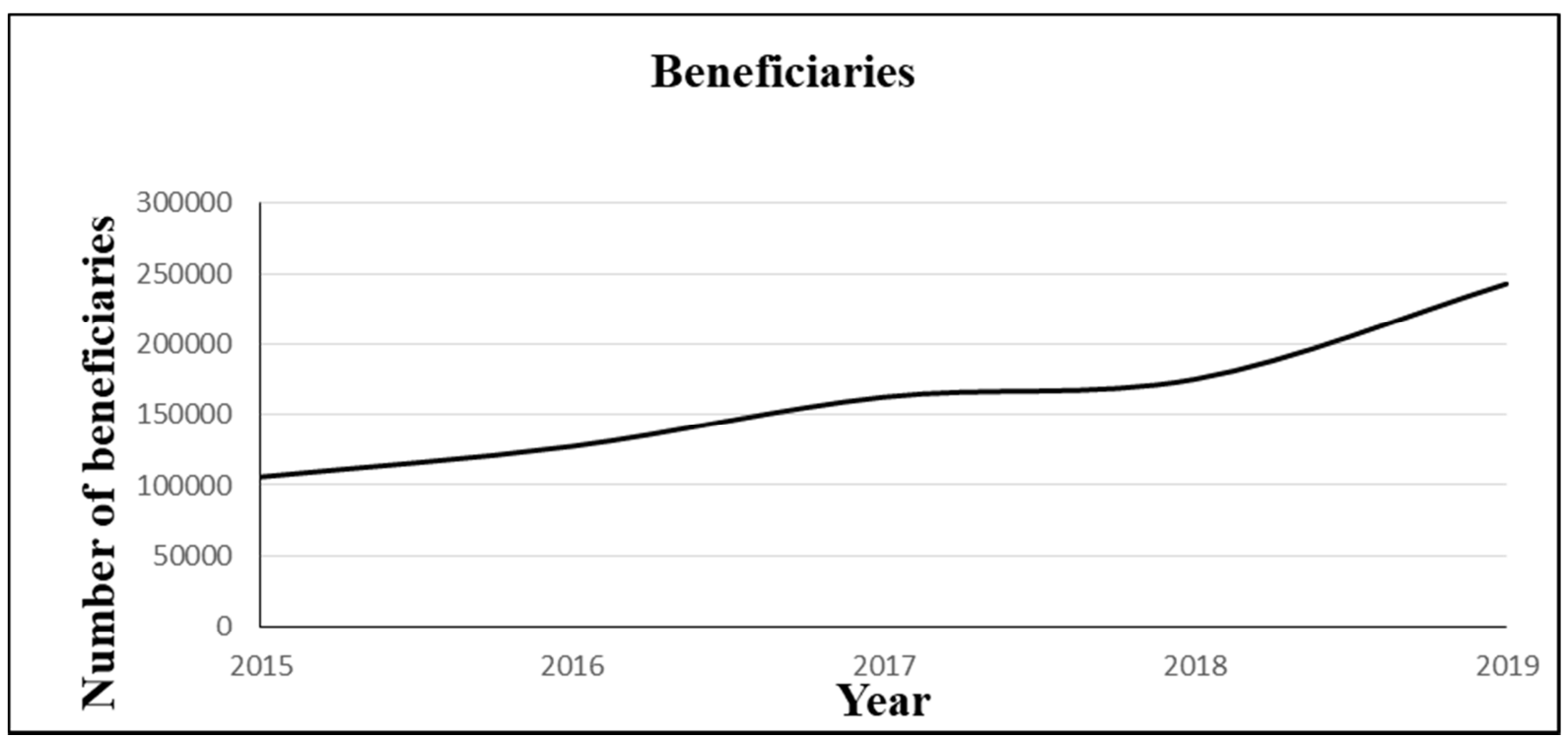

Figure 5. Average Number of Beneficiaries of HA Operations from 2015 to 2019.

The graphical presentations of the financial resource utilization in the year 2015 through 2019 reveals an increasing trend as shown in Figure 6. 


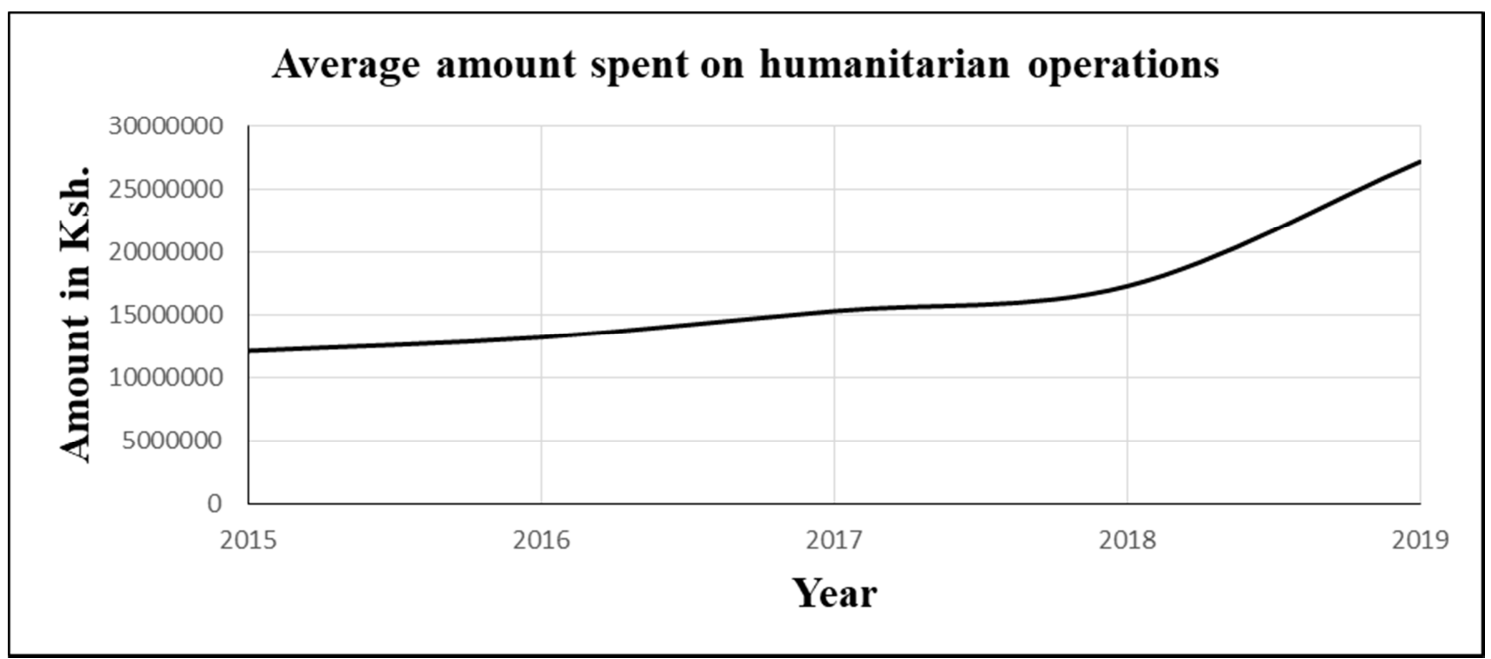

Figure 6. Average of Total Expenses Incurred in HA Operations from 2015 to 2019.

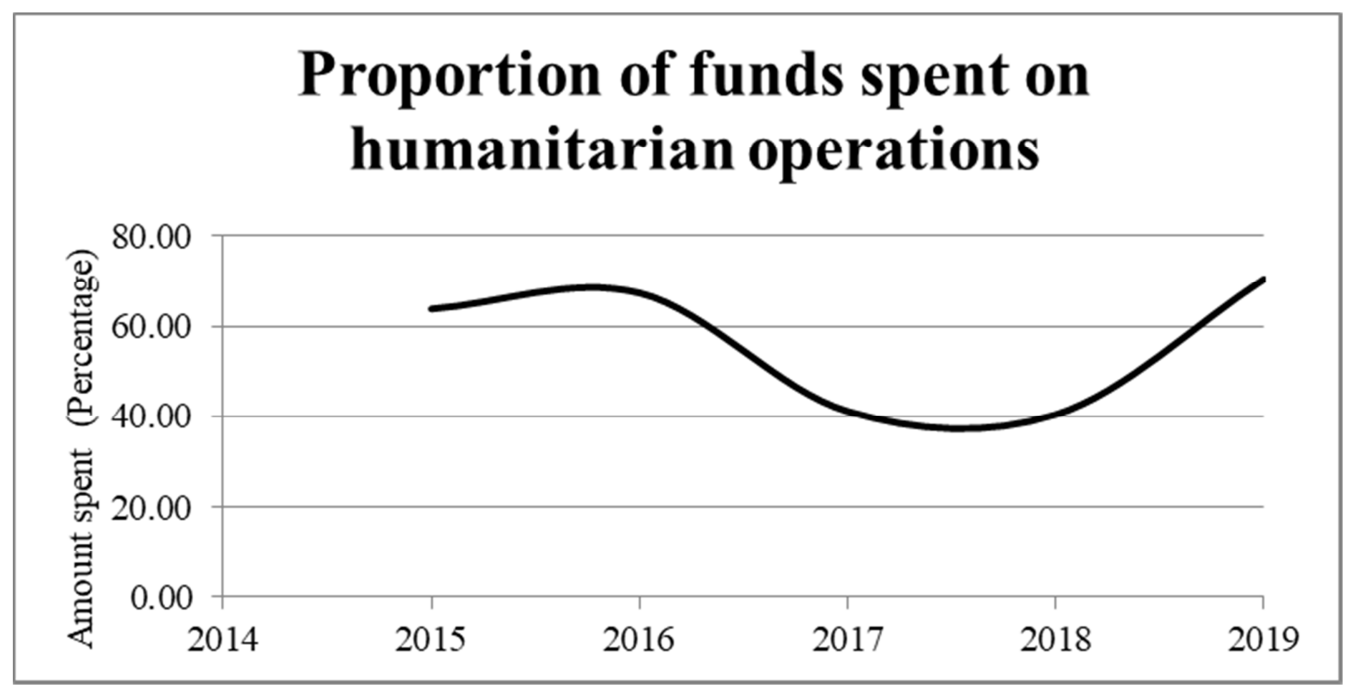

Figure 7. Proportion of Funds Spent on Humanitarian Operations.

\section{Conclusion}

From the study findings, it could be concluded that supply chain responsiveness had a positive significant influence on performance of humanitarian aid organizations in Kenya. The study showed that there was a strong relationship between supply chain responsiveness and performance of HAOs. The findings of the study revealed that humanitarian aid organizations in Kenya have supply chains designed to be responsive to the needs of vulnerable populations. The humanitarian supply chains are designed to evaluate, consider and cover needs of vulnerable people quickly while enabling a view of the movements of materials along the supply chains. However, the ability of humanitarian supply chains to respond quickly to emergencies and disasters is a challenging task influenced by various challenges facing humanitarian supply chains. This means that despite the supply chains being designed to be responsive to emergencies, there is still an element of sluggishness in most humanitarian supply chains in Kenya resultant from the challenges faced. This shows lack of preparedness by humanitarian aid organizations in responding to emergencies and disasters. Supply chain responsiveness reduces the time taken to respond to emergencies hence saving many lives and improving resource utilizations by the aid organizations.

From the findings, there is need for supply chains to be responsive as triggered by the various disasters and situations disrupting communities at large in Kenya. The findings indicated that Kenya has been exposed to a variety of disasters, which are broadly categorized based on their origin as either manmade (anthropogenic) or natural in nature. Commonly identified natural disasters in Kenya included disease outbreaks, plagues/invasions, floods, landslides/mudslides, droughts and famine. Other natural disasters (geophysical in nature) that can be utterly devastating but occur less frequently in Kenya included earthquakes and volcanic eruptions. Common manmade disasters identified included structural/buildings collapse, chemical leaks, oil spillovers, manmade fires, terrorist activities, human conflicts, traffic accidents and politically instigated violence between tribes/groups. The diversity, frequency of occurrence and magnitude of the disasters has 
been on the rise in the recent times resulting in increase in number of people affected. To increase supply chain responsiveness, humanitarian aid organizations have adopted various strategies such as modularization, postponement, shortened lead times and prior transport and capacity planning. The driving forces making humanitarian aid organizations to design responsive supply chains emerged as the need to rescue lives, pressure from donors and the increased number of disasters and emergencies in the contemporary period.

Equally, it could be concluded that waste management had a positive influence on performance of humanitarian aid organizations. Waste management is a continuous exercise in humanitarian supply chains involving identification of nonvalue adding activities in the supply chains and eliminating them. Minimization of wastages enhances resource utilizations in the organizations. Majority of the organizations had managed to eliminate the non-value adding operations in their supply chains but still some humanitarian aid organizations were yet to. One of the major objectives of humanitarian supply chains is adeptness and scaling down the use of rare resources, as this goes against the aim of humanitarian supply chains of saving as many lives as possible. Internal control mechanisms including audits boost effective resource utilizations.

Forms of wastes in humanitarian supply chains emerging from the findings of this study included corruption and diversion of funds. High rates of diversion of funds decreases the range of support for those that need it while creating interest for unknown groups of people who were never meant to be the beneficiaries. This affects the value, nature and necessity of the assistance. Concisely, disasters and pandemics provide a smokescreen for dubious transactions for personal benefit with no or little scrutiny. This explains the increase in money-minting schemes by disasterpreneurs. Mechanisms of addressing supply chain wastes in the process of disaster containment included elimination of the import and tax charges. In addition, punishments were imposed on people who abused services and annulments were made immediately with a binding clarification. Checks and balances also emerged to be a control against theft and use of goods made for vulnerable people for private gains. Other internal control mechanisms include audits boosting effective resource utilizations. Concisely, most humanitarian aid organizations had partially implemented leagility design in their supply chains knowingly or unknowingly. Despite the implementation of supply chain leagility, humanitarian aid organizations still witnessed elements of sluggish response, wastage in the supply chains and disruptions of the chains, all affecting the efficient and effective handling of emergency assistance.

\section{Recommendations of the Study}

Humanitarian aid organizations operate in a volatile, uncertain, complex and ambiguous environment due to changing needs of vulnerable people. To achieve and sustain a supply chain that is responsive to the changing needs and volatile environment, there is a need for organizations to design and implement a supply chain that incorporates agility and lean operation across the value chain. Humanitarian aid organizations are recommended to improve their supply chain leagility by exploring and adopting advanced and emerging technologies such as big data analytics, internet of things, cloud computing, machine learning, artificial intelligence and block chain. Furthermore, it is advisable for humanitarian aid organizations to explore hybrid supply chain approach that allows it to switch between agile and lean depending on market dynamics and environment.

The study recommends for a creation of a disaster preparedness plan that gives the way forward in times of tragedies or natural disasters. This plan should consider all types of hazards every particular place is susceptible to and maybe what is unlikely. Supply chain risk propagation is better effective when companies get the earliest possible warning of possible disastrous occurrences. Adjusting to potential weather change, analyzing data and testing the supply chain to determine vulnerable points where disasters are more likely to affect organizational operations are all ways to stay prepared for the possibility of the disaster.

It is paramount that Kenya stays prepared to minimize the effect of calamities on people and sources of livelihood. While resource allocations for disaster preparedness are increasing, the culture of preparedness in Kenya is lacking. There is no legal framework and no clear coordination across different types of disaster or across actors. Importantly, there are key things that Kenya is getting right. Links exist between Kenya's preparedness and international processes. This indicates there is a level of commitment by the Kenyan government to establish preparedness activities, and it should be seen as a perfect foundation to build on. Developing Standard Operating Procedures containing many types of disasters is a vital approach that should be prioritized by the Kenyan government. Operating hand in hand with implementing agencies ensures all parties benefit from preparation. Once formulated, these procedures should be restructured from time to time to replicate new observations and internal and external changes.

The findings of this study established that most humanitarian aid organizations had knowingly or unknowingly partially implemented leagility design in their supply chains. This study therefore recommends that supply chains managers should fully adopt leagility design in their humanitarian supply chains. The supply chain professionals should establish strategic collaborative working partnerships and agreements with industry players and experts for example seasoned global freight forwarders, ocean carriers, airlines, overland transporters, critical suppliers and all other humanitarian supply chain actors to allow expertise and near precision responsiveness to needs. Each one of these players apply their operational expertise, assets and networks to what they do best hence creating a leagile supply chain.

This study recommends that donors should increase their funding on humanitarian aid operations, but this benefit 
should come at a price, that donors demand to date with accounts of how their funding is used and to see assessable results. Donors should also demand accountability of humanitarian aid organizations.

\section{References}

[1] Jackson, N. M. (2018). Competitive Advantage and Performance of Heavy Construction Equipment Suppliers Nairobi City County, Kenya (Doctoral Dissertation, Kenyatta University).

[2] Chan, A. T., Ngai, E. W., \& Moon, K. K. (2017). The effects of strategic and manufacturing flexibilities and supply chain agility on firm performance in the fashion industry. European Journal of Operational Research, 259 (2), 486-499.

[3] Manning, L., \& Soon, J. M. (2016). Building strategic resilience in the food supply chain. British Food Journal, 118 (6), 1477-1493.

[4] Chen, I. J., \& Kitsis, A. M. (2017). A research framework of sustainable supply chain management. The International Journal of Logistics Management.

[5] Nakandala, D., \& Lau, H. C. (2019). Innovative adoption of hybrid supply chain strategies in urban local fresh food supply chain. Supply Chain Management: An International Journal.

[6] Montz, B. E., Tobin, G. A., \& Hagelman, R. R. (2017). Natural hazards: explanation and integration. Guilford Publications.

[7] Apte, A., Goncalves, P., \& Yoho, K. (2016). Capabilities and competencies in humanitarian operations. Journal of Humanitarian Logistics and Supply Chain Management, 6 (2), 240-258.

[8] Papadopoulos, T., Gunasekaran, A., Dubey, R., Altay, N., Childe, S. J., \& Fosso-Wamba, S. (2017). The role of Big Data in explaining disaster resilience in supply chains for sustainability. Journal of Cleaner Production, 142, 1108-1118.

[9] Olaogbebikan, J. E., \& Oloruntoba, R. (2017). Similarities between disaster supply chains and commercial supply chains: a SCM process view. Annals of Operations Research, 1-26.

[10] Dubey, R., \& Gunasekaran, A. (2016). The sustainable humanitarian supply chain design: agility, adaptability and alignment. International Journal of Logistics Research and Applications, 19 (1), 62-82.

[11] Datta, P. P. (2017). Enhancing competitive advantage by constructing supply chains to achieve superior performance. Production Planning \& Control, 28 (1), 57-74.

[12] Nayak, R., \& Choudhary, S. (2020). Operational excellence in humanitarian logistics and supply chain management through leagile framework: a case study from a non-mature economy. Production Planning \& Control, 1-16.

[13] Mostafa, S., \& Dumrak, J. (2017). A Waste Elimination Process: An Approach for Lean and Sustainable Manufacturing Systems. In Green Supply Chain Management for Sustainable Business Practice (pp. 111-152). IGI Global.

[14] Bortolotti, T., Romano, P., Martinez-Jurado, P. J., \& MoyanoFuentes, J. (2016). Towards a theory for lean implementation in supply networks. International Journal of Production
Economics, 175, 182-196.

[15] Biazzo, S., Panizzolo, R., \& de Crescenzo, A. M. (2016). Lean management and product innovation: a critical review. In Understanding the Lean Enterprise (pp. 237-260). Springer, Cham.

[16] Abdi, M. R., Labib, A. W., Edalat, F. D., \& Abdi, A. (2018). Integrated Reconfigurable Manufacturing Systems and Smart Value Chain. SPRINGER INTERNATIONAL PU.

[17] Um, J. (2017). The impact of supply chain agility on business performance in a high-level customization environment. Operations management research, 10 (1-2), 10-19.

[18] Gligor, D., Gligor, N., Holcomb, M., \& Bozkurt, S. (2019). Distinguishing between the concepts of supply chain agility and resilience: A multidisciplinary literature review. The International Journal of Logistics Management.

[19] Teece, D., Peteraf, M., \& Leih, S. (2016). Dynamic capabilities and organizational agility: Risk, uncertainty, and strategy in the innovation economy. California Management Review, 58 (4), 13-35.

[20] Bendul, J. C., Rosca, E., \& Pivovarova, D. (2017). Sustainable supply chain models for base of the pyramid. Journal of cleaner production, 162, S107-S120.

[21] Singh, S. C., \& Pandey, S. K. (2015). Lean supply-chain: a state-of-the-art literature review. Journal of Supply Chain Management Systems, 4 (3), 33.

[22] Tatham, P., \& Christopher, M. (Eds.). (2018). Humanitarian logistics: Meeting the challenge of preparing for and responding to disasters. Kogan Page Publishers.

[23] Mohammed, N. D. (2018). Examining the Management and Stewardship of Donor Funds, Relative to Outcomes in Basic Education in Kenya (Doctoral dissertation, St. Thomas University).

[24] Christopher, M., Harrison, A., \& van Hoek, R. (2016). Creating the agile supply chain: issues and challenges. In Developments in logistics and supply chain management (pp. 61-68). Palgrave Macmillan, London.

[25] Nkwunonwo, U., Whitworth, M., \& Baily, B. (2016). A review and critical analysis of the efforts towards urban flood risk management in the Lagos region of Nigeria. Natural Hazards and Earth System Sciences, 16 (2), 349-369.

[26] Dufour, É, Laporte, G., Paquette, J., \& Rancourt, M. È. (2018). Logistics service network design for humanitarian response in East Africa. Omega, 74, 1-14.

[27] Koori, C. (2017). Leagile supply chain practices and supply chain performance of non-governmental health organizations in Nairobi, Kenya (Doctoral dissertation, school of business, university of Nairobi).

[28] Kuria, S. W. (2014). Supply chain leagility and performance of humanitarian organizations in Kenya (Doctoral dissertation, School Of Business, University Of Nairobi).

[29] Abdallah, A. B., \& Nabass, I. H. (2018). Supply chain antecedents of agile manufacturing in a developing country context. Journal of Manufacturing Technology Management.

[30] Skliarov, S., Kaptan, K., \& Khorram-Manesh, A. (2017). Definition and general principles of disasters. KhorramManesh (Ed.). 
[31] Weiss, T. G. (2018). Humanitarian challenges and intervention. Routledge.

[32] Mangan, J., \& Lalwani, C. C. (2016). Global logistics and supply chain management. John Wiley \& Sons.

[33] Clarke, W. S. (2018). Learning from Somalia: the lessons of armed humanitarian intervention. Routledge.

[34] Namagembe, S. (2020). Enhancing service delivery in humanitarian relief chains: the role of relational capital. Journal of Humanitarian Logistics and Supply Chain Management.

[35] Paul, B. K. (2019). Response to and Emergency Relief Efforts for the Selected Disasters. In Disaster Relief Aid (pp. 141194). Palgrave Macmillan, Cham.

[36] Maghsoudi, A., Zailani, S., Ramayah, T., \& Pazirandeh, A. (2018). Coordination of efforts in disaster relief supply chains: the moderating role of resource scarcity and redundancy. International Journal of Logistics Research and Applications, 21 (4), 407-430.

[37] Bealt, J., Fernandez Barrera, J. C., \& Mansouri, S. A. (2016). Collaborative relationships between logistics service providers and humanitarian organizations during disaster relief operations. Journal of Humanitarian Logistics and Supply Chain Management, 6 (2), 118-144.

[38] Sinha, D. (Ed.). (2019). Global Supply Chains and Multimodal Logistics: Emerging Research and Opportunities: Emerging Research and Opportunities. IGI Global.

[39] Fadaki, M., Rahman, S., \& Chan, C. (2019). Leagile supply chain: design drivers and business performance implications. International Journal of Production Research, 1-23.

[40] Purvis, L., Spall, S., Naim, M., \& Spiegler, V. (2016). Developing a resilient supply chain strategy during 'boom' and 'bust'. Production Planning \& Control, 27 (7-8), 579-590.

[41] Qamar, A., \& Hall, M. (2018). Can Lean and Agile organizations within the UK automotive supply chain be distinguished based upon contextual factors? Supply Chain Management: An International Journal.

[42] Galankashi, M. R., \& Helmi, S. A. (2016). Assessment of hybrid Lean-Agile (Leagile) supply chain strategies. Journal of Manufacturing Technology Management.

[43] Ponnusamy, P. (2019). Collaborative Framework Arrangement for Agile/Leagile Procurement and Supply of Humanitarian Food Aid: A Case Study of Malaysia (Doctoral dissertation, Curtin University).

[44] Romme, J., \& Hoekstra, S. (Eds.). (1992). Integral Logistic Structures: Developing Customer-oriented Goods Flow. Industrial Press.

[45] Mason-Jones, R., \& Towill, D. R. (1999). Using the information decoupling point to improve supply chain performance. The International Journal of Logistics Management, 10 (2), 13-26.

[46] Goldratt, E. M. (1990). Theory of constraints: What is this thing called and how should it be implemented. The North River, Press Croton on Hudson NY.

[47] Creswell, J. W., \& Poth, C. N. (2017). Qualitative inquiry and research design: Choosing among five approaches. Sage publications.
[48] Rahi, S. (2017). Research design and methods: A systematic review of research paradigms, sampling issues and instruments development. International Journal of Economics \& Management Sciences, 6 (2), 1-5.

[49] Mujere, N. (2016). Sampling in research. In Mixed methods research for improved scientific study (pp. 107-121). IGI Global.

[50] In, J. (2017). Introduction of a pilot study. Korean journal of anesthesiology, $70(6), 601$.

[51] Trafimow, D. (2017). Using the coefficient of confidence to make the philosophical switch from a posteriori to a priori inferential statistics. Educational and Psychological Measurement, 77 (5), 831-854.

[52] Ebert, J. F., Huibers, L., Christensen, B., \& Christensen, M. B. (2018). Or web-based questionnaire invitations as a method for data collection: cross-sectional comparative study of differences in response rate, completeness of data, and financial cost. Journal of medical Internet research, 20 (1), e24.

[53] Rodríguez-Espíndola, O., Chowdhury, S., Beltagui, A., \& Albores, P. (2020). The potential of emergent disruptive technologies for humanitarian supply chains: the integration of block chain, Artificial Intelligence and 3D printing. International Journal of Production Research, 1-21.

[54] Iyengar, V., \& Bharathi, S. V. (2018). Bibliometric Analysis of Lean, Agile, and Leagile Supply Chains in Automobile Industry (1990-2017). International Journal of Information Systems and Supply Chain Management (IJISSCM), 11 (3), $22-45$.

[55] Hassani, Y., Ceauşu, I., \& Iordache, A. (2020, July). Lean and Agile model implementation for managing the supply chain. In Proceedings of the International Conference on Business Excellence (Vol. 14, No. 1, pp. 847-858). Sciendo.

[56] Micheli, G. J., Trucco, P., Sabri, Y., \& Mancini, M. (2019). Modularization as a system life cycle management strategy: Drivers, barriers, mechanisms and impacts. International Journal of Engineering Business Management, 11, 1847979018825041 .

[57] Allaoui, H., Guo, Y., \& Sarkis, J. (2019). Decision support for collaboration planning in sustainable supply chains. Journal of Cleaner Production, 229, 761-774.

[58] Bader Sheikh, S. (2020). Essays on the Economics of Natural Disasters (Doctoral dissertation, UC Santa Barbara).

[59] Kassambara, A. (2017). Practical guide to principal component methods in R: PCA, M (CA), FAMD, MFA, HCPC, factoextra (Vol. 2). STHDA.

[60] Gogtay, N. J., \& Thatte, U. M. (2017). Principles of correlation analysis. Journal of the Association of Physicians of India, 65 (3), 78-81.

[61] Akoglu, H. (2018). User's guide to correlation coefficients. Turkish journal of emergency medicine, 18 (3), 91-93.

[62] Wogi, A. A., Wakweya, S. T., \& Tesfay, Y. Y. (2018). Determinants of Time-to-Under-Five Mortality in Ethiopia: Comparison of Parametric Shared Frailty Models. International Journal of Biomedical and Clinical Engineering (IJBCE), 7 (1), 1-24. 
[63] Jahre, M. (2017). Humanitarian supply chain strategies-a review of how actors mitigate supply chain risks. Journal of Humanitarian Logistics and Supply Chain Management.

[64] Ganguly, K. K., Padhy, R. K., \& Rai, S. S. (2017). Managing the humanitarian supply chain: a fuzzy logic approach. International Journal of Disaster Resilience in the Built Environment.

[65] Behl, A., \& Dutta, P. (2019). Humanitarian supply chain management: a thematic literature review and future directions of research. Annals of Operations Research, 283 (1), 10011044 .

[66] Agarwal, S., Kant, R., \& Shankar, R. (2019). Humanitarian supply chain management frameworks. Benchmarking: An International Journal.

[67] Munyoro, J. (2020). Optimizing humanitarian food relief distribution through local clusters.
[68] Ballé, M., Jones, D. T., Chaize, J., \& Fiume, O. J. (2017). Lean Strategy: Using Lean to Create Competitive Advantage, Unleash Innovation, and Deliver Sustainable Growth. McGraw-Hill Education.

[69] Ye, Y., \& Yan, H. (2020). Disaster Relief Supply Management. In Natural Hazards-Impacts, Adjustments \& Resilience. IntechOpen.

[70] Roddy, S., Strange, J. M., \& Taithe, B. (2018). The Charity Market and Humanitarianism in Britain, 1870-1912. Bloomsbury Academic.

[71] Kabetu, D. G., \& Iravo, M. A. (2018). Influence of strategic leadership on performance of international humanitarian organizations in Kenya. International Academic Journal of Innovation, Leadership and Entrepreneurship, 2 (2), 113-135. 